\title{
Highly efficient water oxidation via a bimolecular reaction mechanism on rutile structured mixed-metal oxyfluorides
}

\author{
Zahra Gohari-Bajestani, ${ }^{1 *}$ Xiao Wang, ${ }^{2}$ Amandine Guiet, ${ }^{1}$ Romain Moury, ${ }^{1}$ Jean-Marc Grenèche, ${ }^{1}$ \\ Annie Hémon-Ribaud, ${ }^{1}$ Yuxuan Zhang, ${ }^{3}$ Daniel Chartrand, ${ }^{3}$ Vincent Maisonneuve, ${ }^{1}$ Ali \\ Seifitokaldani, ${ }^{2 *}$ Nikolay Kornienko, ${ }^{3 *}$ Jérôme Lhoste ${ }^{1 *}$
}

${ }^{1}$ Institut des Molécules et Matériaux du Mans (IMMM), UMR 6283 CNRS, Le Mans Université, Avenue Olivier Messiaen, 72085 Le Mans Cedex 9, France

${ }^{2}$ Department of Chemical Engineering, McGill University, 3610 University Street, Montréal, Québec H3A 0C5, Canada

${ }^{3}$ Department of Chemistry, Université de Montréal, 1375 Ave. Thérèse-Lavoie-Roux, Montréal, Québec, H2V 0B3, Canada

Equal Contribution

*corresponding authors: jerome.lhoste@univ-lemans.fr, nikolay.kornienko@umontreal.ca, and ali.seifitokaldani@mcgill.ca

\begin{abstract}
Mixed-metal oxides are generally considered to be the highest-performance catalysts for alkaline water oxidation. Despite significant efforts dedicated to understanding and accelerating their efficiency, most works have been limited investigations of $\mathrm{Ni}, \mathrm{Co}$, and $\mathrm{Fe}$ oxides, thus overlooking beneficial effects of hetero-anion incorporation. To this end, we report on the development of $\mathrm{Co}_{0.5} \mathrm{Fe}_{0.5} \mathrm{O}_{0.5} \mathrm{~F}_{1.5}$ oxyfluoride materials featuring a rutile crystal structure and porous morphology via a scalable and green synthetic route. The catalyst surface, enhanced through electron withdrawing effects imparted by the fluoride ions, give rise to highly effective catalytic sites for electrochemical water oxidation. In particular, their performance across metrics of Tafel slope $(27 \mathrm{mV} / \mathrm{dec})$, mass activity ( $846 \mathrm{~A} / \mathrm{g}$ at $1.53 \mathrm{~V}$ vs. RHE), turnover frequency (21/s at $1.53 \mathrm{~V}$ vs. RHE), overpotential (220 $\mathrm{mV}$ for $10 \mathrm{~mA} / \mathrm{cm}^{2}$ ), and stability (27 days of continuous operation) largely surpasses most known Cobased catalysts. Mechanistic studies suggest that this performance is driven by a bimolecular, oxygen coupling reaction mechanism through proximal active sites on the catalyst surface, thus enabling a new avenue for achieving accelerated oxygenic electrocatalysis.
\end{abstract}




\section{Introduction}

Impacts on global climate and environmental decay are increasingly evident as consequences of human activities ${ }^{1}$. Mitigating these effects will ultimately be underpinned by the transition to sustainable means of energy harvesting and consumption, within which electrochemical technologies stand to play a critical role ${ }^{2-4}$. Widespread adoption of electrochemical water and $\mathrm{CO}_{2}$ reduction to form $\mathrm{H}_{2}$ or $\mathrm{C}$-based fuels is hampered by the kinetics of the oxygen evolution reaction (OER) and thus, much work in the field is dedicated towards OER catalyst discovery ${ }^{5}$. To this end, mixed-metal oxides have emerged as the top class of materials for this reaction in alkaline conditions ${ }^{6}$. The recent decade of work in the field has yielded important gains in understanding the roles of incorporating $\mathrm{Fe}$ impurities, lattice strain, substrate effects, interfaces and exfoliation. ${ }^{7-11}$ In an orthogonal direction, the modification of the catalytically active sites through hetero-element incorporation has yielded substantial gains in performance over purely $\mathrm{Ni} / \mathrm{Co} / \mathrm{Fe}$ oxides, though most efforts focus on cationic incorporation $^{12}$. In contrast, anionic incorporation is seldom used, largely due to synthetic challenges, especially in the direction of fluoride substitution. However, initial reports suggest that hetero-anionic compounds hold much promise as OER catalysts, though the factors driving these observations are not fully settled ${ }^{13-19}$. Often, metal oxides catalyze the OER through sequential proton-coupled electron transfer steps. This inevitably limits their performance via scaling relations as all intermediates share a $\mathrm{M}-\mathrm{O}$ bond. ${ }^{20}$ Breaking these scaling relations for enhanced OER performance can be accomplished by accessing new reaction mechanisms such as radical oxygen coupling and lattice oxygen involvement, and the discovery of new OER catalyst compositions ultimately underpins access to such reaction pathways.

Numerous synthetic routes have been used to prepare functional transition metal oxyfluorides to control the chemical composition with specific fluorination degree, particle size, morphology, and stabilization of desired crystal structures ${ }^{21-25}$. In this work, we report on the two-step preparation of a new cobalt iron oxyfluoride with a rutile type structure, $\mathrm{Co}_{0.5} \mathrm{Fe}_{0.5} \mathrm{O}_{0.5} \mathrm{~F}_{1.5}$, obtained by calcination of the hydrated fluoride $\mathrm{CoFeF}_{5}\left(\mathrm{H}_{2} \mathrm{O}\right)_{7}$. Subsequent electrocatalytic evaluations unveiled that $\mathrm{Co}_{0.5} \mathrm{Fe}_{0.5} \mathrm{O}_{0.5} \mathrm{~F}_{1.5}$ is one of the highest performing cobalt-based OER catalysts reported to date, considering metrics of overpotential, Tafel slope, mass activity, and stability. Complementary lines of computational and mechanistic studies were carried out to elucidate that the existence of a bimolecular reaction mechanism that is deemed to be the origin of the high efficiency of $\mathrm{Co}_{0.5} \mathrm{Fe}_{0.5} \mathrm{O}_{0.5} \mathrm{~F}_{1.5}$. 


\section{Catalyst Synthesis and Characterizations}

A soft chemistry method was chosen to generate $\mathrm{Co}_{0.5} \mathrm{Fe}_{0.5} \mathrm{O}_{0.5} \mathrm{~F}_{1.5}$. A detailed description can be found in the supporting information. In brief, the catalyst was prepared in a controlled thermal decomposition of a hydrated fluoride precursor in mild conditions. The precursor $\mathrm{CoFeF}_{5}\left(\mathrm{H}_{2} \mathrm{O}\right)_{7}$ was precipitated by thermally assisted evaporation of a hydrofluoric acid (HF) solution containing metallic salts. The thermal decomposition of $\mathrm{CoFeF}_{5}\left(\mathrm{H}_{2} \mathrm{O}\right)_{7}$ was followed by combined thermogravimetric analysis (TGA) and thermodiffraction. Three thermal events appeared on the TGA curve and thermodiffractograms that correspond to the structural evolution of $\mathrm{CoFeF}_{5}\left(\mathrm{H}_{2} \mathrm{O}\right)_{7}$ across four domains (Fig. 1a and b): (i) stability of $\mathrm{CoFeF}_{5}\left(\mathrm{H}_{2} \mathrm{O}\right)_{7}\left(\mathrm{RT}-100^{\circ} \mathrm{C}\right.$, green), (ii) dehydration of $\mathrm{CoFeF}_{5}\left(\mathrm{H}_{2} \mathrm{O}\right)_{7}$ $\left(100-220^{\circ} \mathrm{C}\right.$, blue), (iii) formation of $\mathrm{Co}_{0.5} \mathrm{Fe}_{0.5} \mathrm{O}_{0.5} \mathrm{~F}_{1.5}$ with the rutile structure type $\left(220-280^{\circ} \mathrm{C}\right.$, purple) and (iv) formation of oxides, $\mathrm{CoO}$ and $\mathrm{CoFe}_{2} \mathrm{O}_{4}\left(\mathrm{~T}^{\circ} \mathrm{C}>280^{\circ} \mathrm{C}\right.$, red). To sum up, $\mathrm{CoFeF}_{5}\left(\mathrm{H}_{2} \mathrm{O}\right)_{7}$ undergoes the following decompositions upon thermal treatment according to the reactions (1), (2) and (3). The experimental weight loss values are in good agreement with theoretical values (theo $\mathrm{wt} \%$, $\exp w t \%$ ):

(1) $100^{\circ} \mathrm{C}-220^{\circ} \mathrm{C}: \mathrm{Co}^{2+} \mathrm{Fe}^{3+} \mathrm{F}_{5}\left(\mathrm{H}_{2} \mathrm{O}\right)_{7} \rightarrow \mathrm{Co}^{2+} \mathrm{Fe}^{3+} \mathrm{F}_{5}+7 \mathrm{H}_{2} \mathrm{O}(37.5 \%, 38.0 \%)$

(2) $220^{\circ} \mathrm{C}-280^{\circ} \mathrm{C}: \mathrm{Co}^{2+} \mathrm{Fe}^{3+} \mathrm{F}_{5}+\mathrm{H}_{2} \mathrm{O} \rightarrow 2 \mathrm{Co}^{2+}{ }_{0.5} \mathrm{Fe}^{3+}{ }_{0.5} \mathrm{O}_{0.5} \mathrm{~F}_{1.5}+2 \mathrm{HF}(6.6 \%, 6.7 \%)$

(3) $>280^{\circ} \mathrm{C}: 2 \mathrm{Co}^{2+}{ }_{0.5} \mathrm{Fe}^{3+}{ }_{0.5} \mathrm{O}_{0.5} \mathrm{~F}_{1.5}+3 / 2 \mathrm{H}_{2} \mathrm{O} \rightarrow{ }^{1 / 2} \mathrm{Co}^{2+} \mathrm{O}+1 / 2 \mathrm{Co}^{2+} \mathrm{Fe}^{3+}{ }_{2} \mathrm{O}_{4}+3 \mathrm{HF}(9.8 \%, 9.2 \%)$

The hydrolysis reactions (2) and (3) are further confirmed by the absence of significant weight loss in the TGA profile performed under dry air at temperatures from $220^{\circ} \mathrm{C}$ (Fig. 1a). 
A disordered model based on metal atoms located in 2a Wyckoff positions (WP) (Co: 50\%, Fe: $50 \%$ confirmed by SEM-EDS, Fig. S7c) and the 4f WP statistically occupied by oxygen atoms (25\%) and fluorine atoms (75\%) was used for Rietveld refinement of $\mathrm{Co}_{0.5} \mathrm{Fe}_{0.5} \mathrm{O}_{0.5} \mathrm{~F}_{1.5}$ PXRD pattern (space group $P 4_{2} / \mathrm{mnm}$ ). A good fit was obtained in spite of the low crystallinity with the cell parameters: $\mathrm{a}=\mathrm{b}=4.6916(5) \AA, \mathrm{c}=3.1098(3) \AA, \mathrm{V}=68.450(1) \AA^{3}$ (Fig. 1e). The broadening of the Bragg diffraction peaks, compared to the diffraction pattern of the precursor (Fig. S1), reveals small coherent diffraction domains. Indeed, an emerging porosity is observed which is likely related to the precursor's decomposition during which $\mathrm{HF}$ and $\mathrm{H}_{2} \mathrm{O}$ gas molecules act as a self-generated porogen (Fig. 1c). Upon thermal treatment $S_{\mathrm{BET}}$ increases from $3 \mathrm{~m}^{2} \cdot \mathrm{g}^{-1}$ to $24 \mathrm{~m}^{2} \cdot \mathrm{g}^{-1}$ confirming the porogen effect of the $\mathrm{H}_{2} \mathrm{O}$ and $\mathrm{HF}$ released. $\mathrm{N}_{2}$ adsorption/desorption isotherms shows type IV hysteresis corresponding to a mesoporous structure and the BJH pore-size distribution analysis (Fig. 1d) confirms an average pore diameter less than $10 \mathrm{~nm}$, in good agreement with the TEM observation (Fig. 1c). ${ }^{57} \mathrm{Fe}$ Mössbauer spectra (Fig. 1f) and the hyperfine data, in particular $\delta=0.39$ and $0.46 \mathrm{~mm} \cdot \mathrm{s}^{-1}$ at 300 and $77 \mathrm{~K}$, respectively, are consistent with the presence of only $\mathrm{Fe}^{3+}$ species with different atomic environments, resulting from: (i) the presence of octahedral units with shared corners and shared edges, (ii) Fe-Co cationic disorder, and (iii) small crystal grain size, consistent with X-ray analysis. X-ray photoelectron spectroscopy was used to measure the electronic structure of both of the $\mathrm{Co}$ and $\mathrm{Fe}$ components in $\mathrm{Co}_{0.5} \mathrm{Fe}_{0.5} \mathrm{O}_{0.5} \mathrm{~F}_{1.5}$. The $\mathrm{Fe} 2 \mathrm{p}_{3 / 2}$ edge could be fit to two components at 710.7 and $712.7 \mathrm{eV}$ (Fig. 1g). These values match that of $\mathrm{Fe}^{3+}$ and fall between that of $\mathrm{Fe}$ in a pure oxide and a pure fluoride environment. The Co $2 \mathrm{p}_{3 / 2}$ peak has a primary feature at $781.7 \mathrm{eV}$, with a satellite at $786.4 \mathrm{eV}$ which is in between the expected ranges of pure Co fluorides and oxides (Fig. 1h). These measurements illustrate the strong inductive effects imparted through the fluoride components within the lattice hypothesized earlier to influence the catalytic properties of the composite material. 

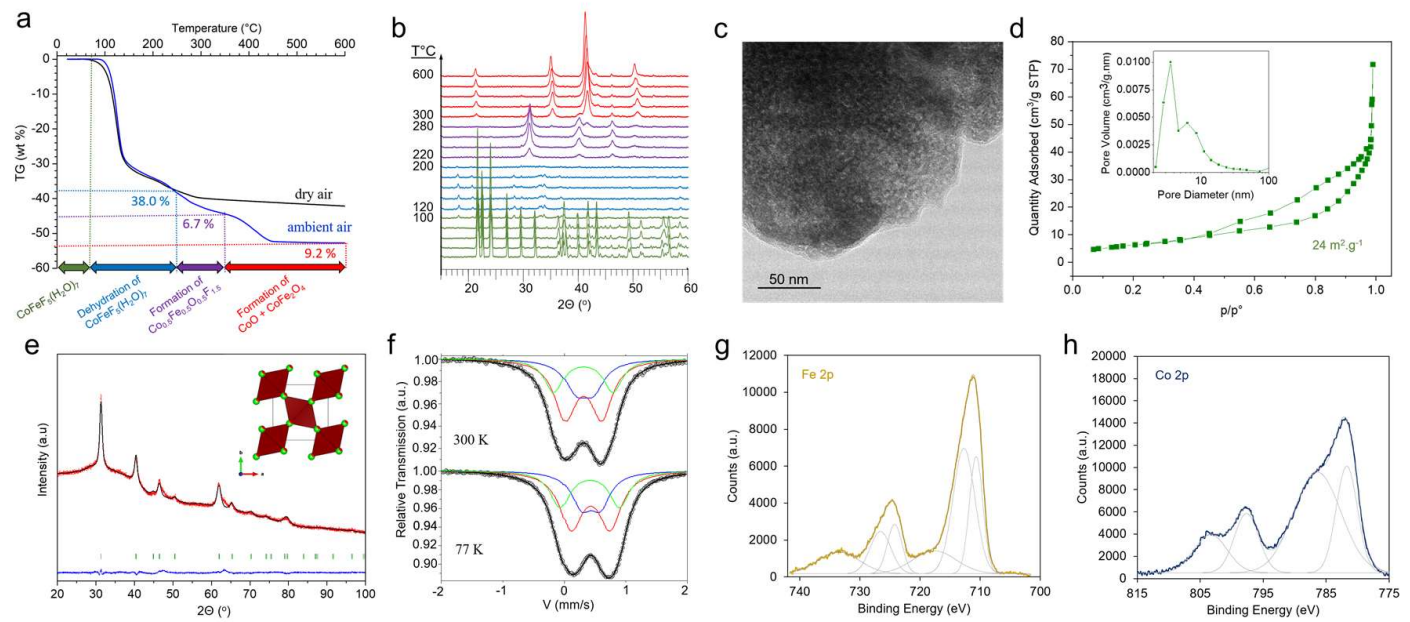

Figure 1: TGA analyses under dry air (line dashed) and ambient air of $\mathrm{CoFeF}_{5}\left(\mathrm{H}_{2} \mathrm{O}\right)_{7}$ (a). Thermal evolution of the X-ray diffractograms under ambient air of $\mathrm{CoFeF}_{5}\left(\mathrm{H}_{2} \mathrm{O}\right)_{7}$ (b). TEM micrographs (c) and $\mathrm{N}_{2}$ adsorption/desorption isotherm (the inset corresponds to the BJH pore size distribution analyzed from the desorption branch) (d) of $\mathrm{Co}_{0.5} \mathrm{Fe}_{0.5} \mathrm{O}_{0.5} \mathrm{~F}_{1.5}$. Rietveld refinement of the PXRD pattern of $\mathrm{Co}_{0.5} \mathrm{Fe}_{0.5} \mathrm{O}_{0.5} \mathrm{~F}_{1.5}$ with the inset illustrating the [100] projection of $\mathrm{Co}_{0.5} \mathrm{Fe}_{0.5} \mathrm{O}_{0.5} \mathrm{~F}_{1.5}$ structure (e) ${ }^{57} \mathrm{Fe}$ Mössbauer spectra recorded at $2 \mathrm{~mm} \cdot \mathrm{s}^{-1}$ at 300 and $77 \mathrm{~K}$ (f). XPS spectra illustrate the electron withdrawing effects of the fluoride components on the Fe (g) and Co (h) components.

\section{Electrocatalytic Performance}


The catalytic properties of $\mathrm{Co}_{0.5} \mathrm{Fe}_{0.5} \mathrm{O}_{0.5} \mathrm{~F}_{1.5}$ were next evaluated through a host of electrochemical techniques. In a standard 3-electrodes configuration, a cyclic voltammogram (CV) of the catalyst deposited onto a carbon paper electrode in $1 \mathrm{M} \mathrm{KOH}$ electrolyte showed a redox peak centered at $1.1 \mathrm{~V}$ vs. the reversible hydrogen electrode (RHE). This peak was attributed to the $\mathrm{Co}(\mathrm{II} / \mathrm{III})$ redox couple (Fig. 2a and inset). Electrocatalytic current initiated around $1.4 \mathrm{~V}_{\mathrm{RHE}}$ requires $220 \mathrm{mV}$ overpotential to reach $10 \mathrm{~mA} / \mathrm{cm}^{2}$ and $265 \mathrm{mV}$ to reach $100 \mathrm{~mA} / \mathrm{cm}^{2}$. On the reverse scan, a reductive peak around 1.4 $\mathrm{V}_{\text {RHE }}$ was observed and attributed to the reduction of $\mathrm{Co}$ (IV) back to $\mathrm{Co}$ (III) and was more evident with increasingly positive scan limits in the CV (Fig. 2a inset). These assignments are in agreement with previous observations of Co-oxides the literature ${ }^{26,27}$ while $\mathrm{Fe}$ oxides typically do not show such redox behavior under these conditions ${ }^{28}$. The oxidation peak of the $\mathrm{Co}(\mathrm{III} / \mathrm{IV})$ redox couple was not as visible as it was overshadowed by the catalytic current which initiated alongside of the Co(III/IV) oxidation. This signifies that Co(IV) was likely involved in the OER catalytic cycle. We note that there is probably a surface restructuration that occurs as the redox behavior of the $1^{\text {st }} \mathrm{CV}$ differs from the $2^{\text {nd }}$, though no further changes occur afterward (Fig. S10a,b). This indicates that there may be an initial surface restructuration occurring toward a stable surface induced by the application of positive potentials and the environment of Co becomes $\mathrm{O} / \mathrm{OH}-$ terminated at the surface as suggested by the changes observed on XPS spectra (Fig. S10c-f). Moreover, the peak shift of the $\mathrm{Co}^{+2}$ oxidation into $\mathrm{Co}^{+3}$ to lower value between the $1^{\text {st }}$ and the $2^{\text {nd }}$ cycle is in agreement with an exchange $\mathrm{OH} / \mathrm{F}$ at the surface; the $\mathrm{M}-\mathrm{F}$ is more ionic compared to $\mathrm{M}-\mathrm{O}$ leading to higher potential ${ }^{29}$.

After 1.4 $\mathrm{V}_{\mathrm{RHE}}$, the catalytic current rose exceptionally fast and this was reflected in the low Tafel slope of $27 \mathrm{mV} / \mathrm{dec}$ (Fig. 2b). A similar Tafel slope was measured if the catalyst was deposited on a glassy carbon rotating disk electrode (RDE) at $0.1 \mathrm{mg} / \mathrm{cm}^{2}$ in a configuration with minimized masstransport limitations. In the same configuration, we quantified that mass-activity reached $846 \mathrm{~A} / \mathrm{g}$ at $300 \mathrm{mV}$ overpotential (Fig. 2c). Similarly, the turnover frequency (TOF) was measured to be $21 / \mathrm{s}$ at this voltage, which was quantified by the redox-active Co atoms that were deduced through integration of the redox peaks in the $\mathrm{CV}$ assuming the Co is indeed the OER active site. If measured by the total mass loading, the TOF was approximately 0.46 /s, suggesting that approximately 1 out of every $45 \mathrm{Co}$ atoms was electrochemically active. The fluorine component was deemed important for the catalytic performance of $\mathrm{Co}_{0.5} \mathrm{Fe}_{0.5} \mathrm{O}_{0.5} \mathrm{~F}_{1.5}$ because when the catalyst was annealed at $500^{\circ} \mathrm{C}$ to convert to $\mathrm{CoO} / \mathrm{CoFe}_{2} \mathrm{O}_{4}$, the Tafel slope, onset potential and overall activity significantly diminished (Fig. S11). The stability of $\mathrm{Co}_{0.5} \mathrm{Fe}_{0.5} \mathrm{O}_{0.5} \mathrm{~F}_{1.5}$ was next evaluated through chronopotentiometry, switching between several current densities over the course of 27 days without pause (Fig. 2d). Rotating ring disk electrode (RRDE) measurements confirmed that the current was indeed originating from the OER (Fig. S12). 

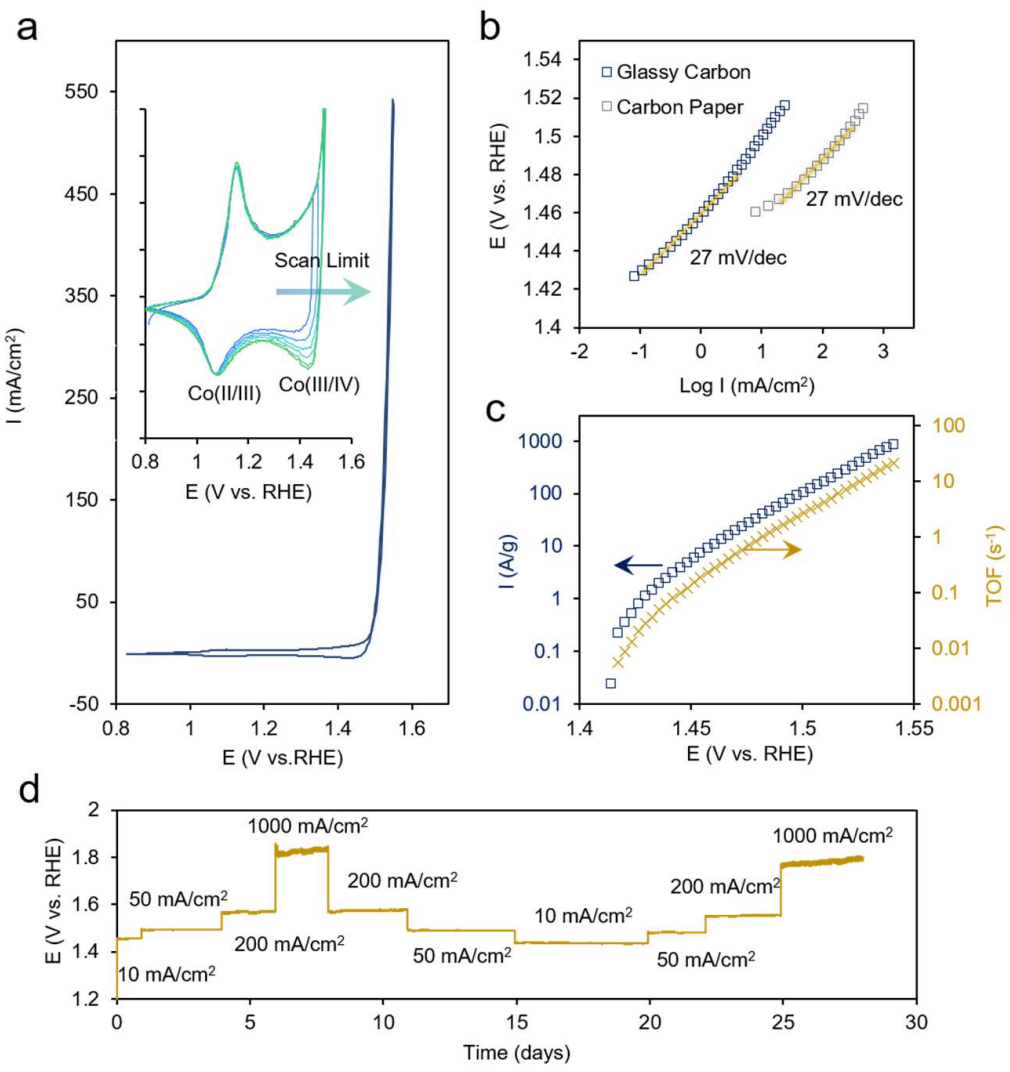

Figure 2: $\mathrm{CV}$ curves of $\mathrm{Co}_{0.5} \mathrm{Fe}_{0.5} \mathrm{O}_{0.5} \mathrm{~F}_{1.5}$ the inset represent $\mathrm{CVs}$ at different scan limits. The increase of scan limit allows to identify the oxidation peak, $\mathrm{Co}_{0.5} \mathrm{Fe}_{0.5} \mathrm{O}_{0.5} \mathrm{~F}_{1.5}$ exhibits 2 redox peaks, at $1.1 \mathrm{~V}_{\text {RHE }}$ and $1.4 \mathrm{~V}_{\mathrm{RHE}}$, just prior to the onset of the OER ( $1^{\text {st }}$ cycle is removed) (a). Tafel plot of $\mathrm{Co}_{0.5} \mathrm{Fe}_{0.5} \mathrm{O}_{0.5} \mathrm{~F}_{1.5}$ obtained on carbon paper and glassy carbon RDE electrodes; similar Tafel slopes are measured on both substrates (b). Plot of the mass activities and TOF as a function of the applied potential, a mass activity of $846 \mathrm{~A} / \mathrm{g}$ and TOF of $21 / \mathrm{s}$ were recorded at $300 \mathrm{mV}$ overpotential (c). Chronopotentiometric evaluation of $\mathrm{Co}_{0.5} \mathrm{Fe}_{0.5} \mathrm{O}_{0.5} \mathrm{~F}_{1.5}$ : the activity did not noticeably decrease through 27 days of measurement (d).

\section{Mechanism Study}

In order to probe the reaction mechanism and understand the roles of $\mathrm{Co}$ and $\mathrm{Fe}$ atoms for $\mathrm{Co}_{0.5} \mathrm{Fe}_{0.5} \mathrm{O}_{0.5} \mathrm{~F}_{1.5}$, we first performed density functional theory (DFT) computations. Here, we chose (110) facet because of its lowest surface energy and thus the most stable surface in rutile structures. ${ }^{24,30}$ Two reaction pathways are considered here, adopting different $\mathrm{O}-\mathrm{O}$ bond formation strategies, which are the water nucleophilic attack (WNA) and the interaction of two metal-oxo units (I2M) (Fig. S13). These two mechanisms are reported to be the primary reaction pathways for the OER. ${ }^{31}$ Two model structures of $\mathrm{Co}_{0.5} \mathrm{Fe}_{0.5} \mathrm{O}_{0.5} \mathrm{~F}_{1.5}$ are proposed for the DFT simulations to shed light on the role of Co and $\mathrm{Fe}$ species, where the switch between $\mathrm{Co}$ and $\mathrm{Fe}$ atoms takes place intermittently (denoted as 
CoFeOF(110)-1) or continuously (denoted as CoFeOF(110)-2). Following the WNA and I2M mechanisms, we tested each intermediate on multiple active sites for each model catalyst, where only the most stable configurations were shown (Fig. 3a and b). For both model catalysts, we noticed that the adsorbed oxyhydroxide intermediate $(* \mathrm{OOH})$ is unstable and tends to decompose into adsorbed oxygen atom $(* \mathrm{O})$ and adsorbed hydroxide $\left({ }^{*} \mathrm{OH}\right)$. We also observed that for $\mathrm{CoFeOF}(110)-1$, when two $* \mathrm{O}$ are placed on the surface, they are prone to relocate at a bridge position where either of them is between $\mathrm{Co}$ and $\mathrm{Fe}$ atoms. We assume that two ${ }^{*} \mathrm{O}$ intermediates favor similar local environments (i.e., both bridge positions are between Co and Fe versus two bridge positions are between different two metal atoms) so that the energy of the system can reach its optimum through relocation. After the relocation of two ${ }^{*} \mathrm{O}$, one ${ }^{*} \mathrm{O}$ in either adjacent unit cell comes closer to each other to form the *O-O* coupling between two $\mathrm{Fe}$ atoms.

From the energy profiles (Fig. 3c and f), it is apparent that the I2M mechanism has a lower energy barrier (4.02 and $3.51 \mathrm{eV}$, for structures 1 and 2, respectively) for its rate-limiting step (RLS, which is the desorption of $\mathrm{O}_{2}$ ) and thus is more favorable than the WNA mechanism (7.77 and 7.91 $\mathrm{eV}$, for structures 1 and 2, respectively) for both model catalysts without any applied potentials (i.e., at $U=0 \mathrm{~V}$ ). For both WNA and I2M mechanisms, their first two steps are the same electrochemical reactions with electron transfer. However, the last two steps in the I2M mechanism are chemical reactions without any electron transfer, whereas the last two steps in the WNA mechanism still contain electron transfer. Therefore, a large enough applied potential can theoretically suppress the limiting energy barrier in the WNA mechanism without any impact on the limiting energy barrier in the I2M mechanism to compel the two limiting energy barriers to equal. However, due to the large difference between the two limiting energy barriers at $U=0 \mathrm{~V}$, only if an applied potential that is greater than $3.75 \mathrm{~V}$ for $\mathrm{CoFeOF}(110)-1$ and $4.40 \mathrm{~V}$ for $\mathrm{CoFeOF}(110)-2$, allows the reaction pathway shift from the I2M to the WNA mechanism. Since the applied potentials employed in this study are much smaller than $3.75 \mathrm{~V}$ and $4.40 \mathrm{~V}$, we posit that the $\mathrm{I} 2 \mathrm{M}$ mechanism containing an $* \mathrm{O}-\mathrm{O} *$ coupling is the reaction pathway for $\mathrm{Co}_{0.5} \mathrm{Fe}_{0.5} \mathrm{O}_{0.5} \mathrm{~F}_{1.5}$ catalyst.

Furthermore, a comparison of the energy profiles on both model catalysts, illustrates that $\mathrm{CoFeOF}(110)-2$ has a lower limiting energy barrier at $U=0 \mathrm{~V}$ and requires a higher applied potential to shift from the I2M pathway to the WNA pathway. This implies that the structure of $\mathrm{CoFeOF}(110)-2$ following the WNA pathway is more favorable for the OER, and the existence of Co benefits the reaction. To further shed light on the reaction mechanism, we calculated the Bader charge distribution and the charge density difference to analyze the ${ }^{*} \mathrm{O}-\mathrm{O} *$ coupling sites for $\mathrm{CoFeOF}(110)-1$ (Fig. $3 \mathrm{~d}$ and e) and $\mathrm{CoFeOF}(110)-2$ (Fig. $3 \mathrm{~g}$ and h). The cyan contours around the metal atoms and the yellow regions around the $* \mathrm{O}-\mathrm{O} *$ indicate that the metal atoms lose electrons, while the $* \mathrm{O}-\mathrm{O} *$ entities gain electrons. This can be also concluded from the Bader charge distribution. More importantly, the Bader charger distribution implies that $\mathrm{Fe}$ atoms lose more electrons than $\mathrm{Co}$ atoms, which is further 
confirmed by the fact that the ${ }^{*} \mathrm{O}$ connected to $\mathrm{Fe}$ gains more electrons. This means the interaction between $\mathrm{Fe}$ and $* \mathrm{O}$ is stronger than between $\mathrm{Co}$ and $* \mathrm{O}$. The lowest adsorption energy of $\mathrm{O}_{2}$ at the bridge sites between two adjacent cations: $\mathrm{Fe} / \mathrm{Fe}, \mathrm{Fe} / \mathrm{Co}$, and $\mathrm{Co} / \mathrm{Co}$ (Fig. S14) was found for $\mathrm{Fe} / \mathrm{Co}$. This feature confirms that the unbalanced interactions between $\mathrm{Co}-\mathrm{O}$ and $\mathrm{Fe}-\mathrm{O}$ results in unstable *O$\mathrm{O}^{*}$ on $\mathrm{CoFeOF}(110)-2$, thereby making $\mathrm{O}_{2}$ desorption easier. This inference is also implied from the additional Bader charge distribution and the charge density difference (Fig. S15), which illustrates the uneven charge density distribution in ${ }^{*} \mathrm{O}-\mathrm{O} *$ between $\mathrm{Co}$ and $\mathrm{Fe}$ due to the different capabilities of $\mathrm{Co}$ and $\mathrm{Fe}$ to donate electrons to $* \mathrm{O}-\mathrm{O} *$. DFT calculations performed herein demonstrate that the I2M mechanism containing an ${ }^{*} \mathrm{O}-\mathrm{O} *$ coupling is the most favorable reaction pathway and the $\mathrm{O}_{2}$ desorption is the RLS. In addition, DFT results posit that both Co and Fe play a critical role in the enhanced performance of the OER. 
a
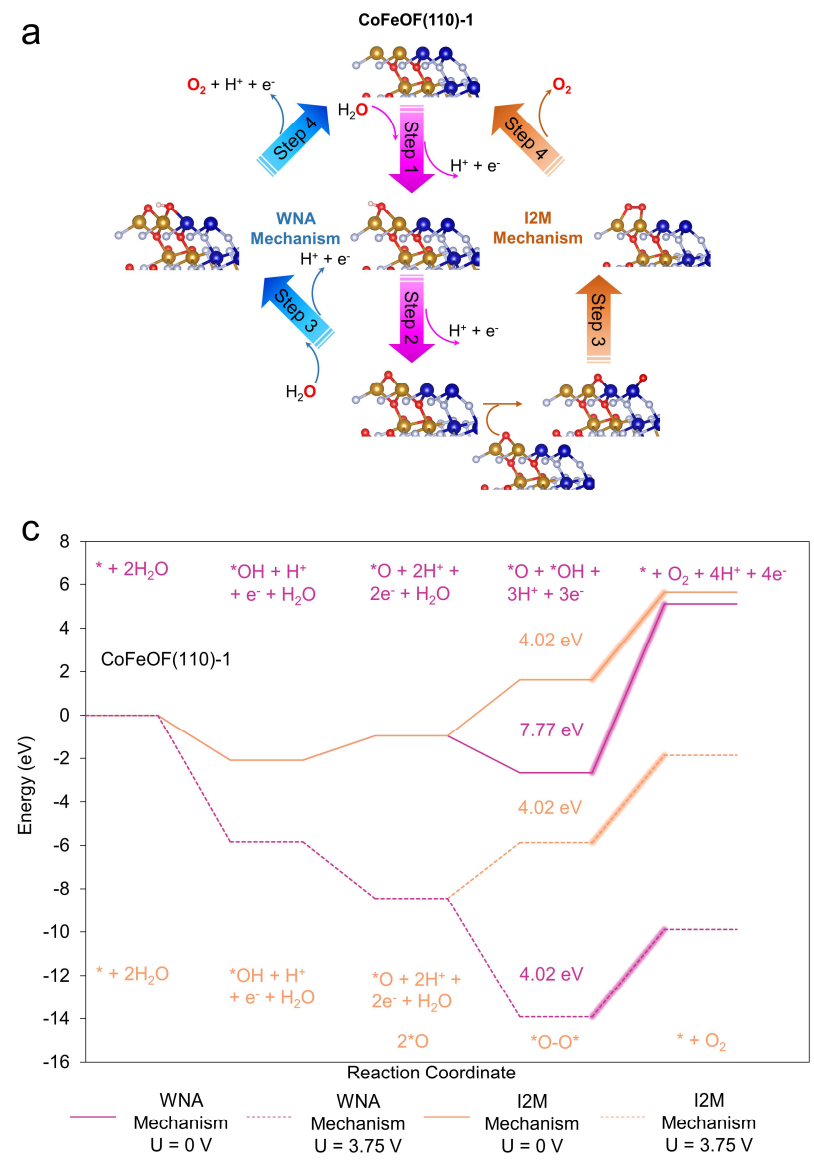

f

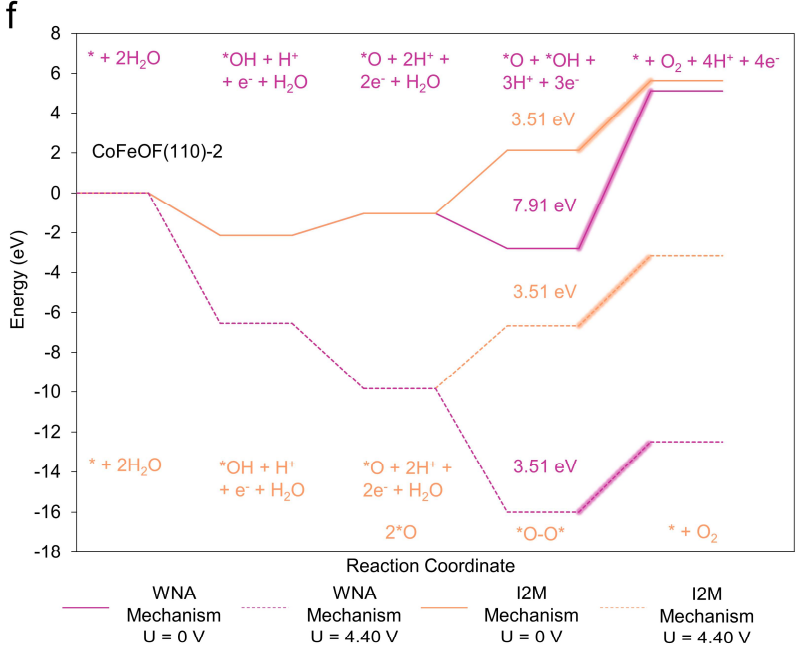

b

CoFeOF(110)-2

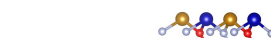

$\mathrm{O}_{2}+\mathrm{H}^{+}+\mathrm{e}^{-} \quad \mathrm{H}^{-}$

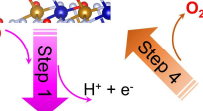

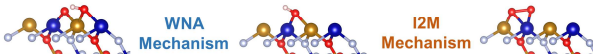

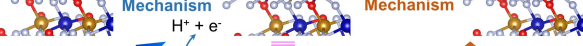

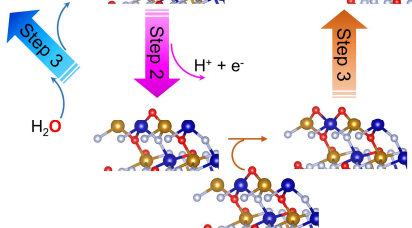

d

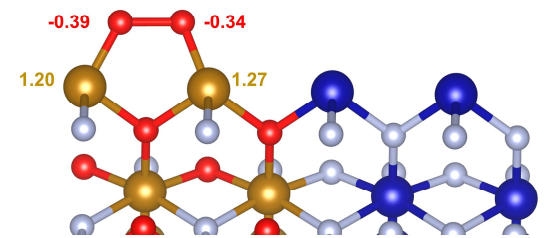

e

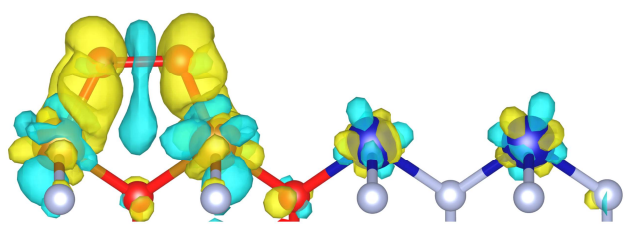

g

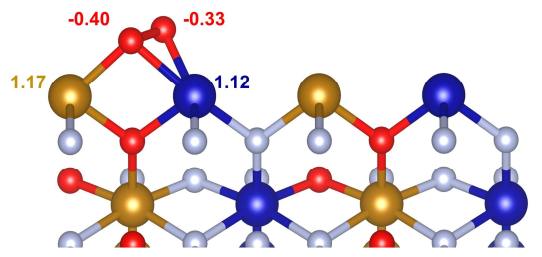

h

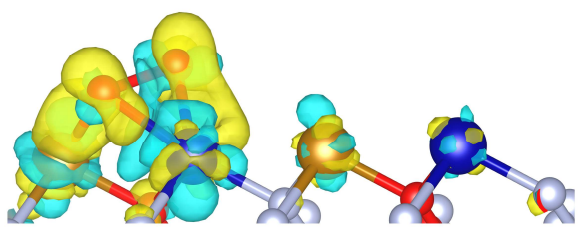

Figure 3: Comparison of the WNA and I2M mechanisms for $\mathrm{CoFeOF}(110)-1$ (a) and $\mathrm{CoFeOF}(110)-2$

(b). The cobalt, iron, oxygen, and fluorine atoms are marked as blue, gold, red, and silver, respectively. Energy profiles for $\mathrm{CoFeOF}(110)-1$ (c) and $\mathrm{CoFeOF}(110)-2$ (f) with applied potentials. The highlights represent the rate-limiting steps with the values of the relevant energy barriers labelled. The Bader charge distribution and the corresponding charge density difference at the $* \mathrm{O}-\mathrm{O} *$ coupling sites for $\operatorname{CoFeOF}(110)-1$ (d, e) and $\operatorname{CoFeOF}(110)-2$ (g, h). The yellow and cyan contours denote electron accumulation and depletion, respectively. 
We next took to further elucidating the mechanism of the OER on $\mathrm{Co}_{0.5} \mathrm{Fe}_{0.5} \mathrm{O}_{0.5} \mathrm{~F}_{1.5}$ catalyst surfaces through $\mathrm{pH}$-dependent electrochemical experiments. $\mathrm{CVs}$ of the catalyst were recorded from pH 11 to nominally pH 14 (Fig. 4a). At pH 11, the current attributed to Co redox peaks was considerably lower until approximately $\mathrm{pH} 12$, whereas the reduction of $\mathrm{Co}(\mathrm{IV})$ increased continually until $\mathrm{pH} 14$. Only at $\mathrm{pH} 14$, the same amount of charge was integrated under the Co(IV) reduction as the $\mathrm{Co}(\mathrm{III})$ reduction (Fig. 4b). In addition to the rise in $\mathrm{Co}(\mathrm{IV})$, the catalytic current also increased more rapidly at higher $\mathrm{pH}$ electrolytes, quantified here by a decrease in Tafel slope (Fig. 4c). Finally, the absolute potential (here plotted on vs. the Standard Hydrogen Electrode, SHE) of the Co redox potentials and the catalytic current exhibited differing shifts as a function of electrolyte $\mathrm{pH}$ (Fig. 4d). First, the $\mathrm{Co}(\mathrm{II} / \mathrm{III})$ redox couple shifted $91 \mathrm{mV} / \mathrm{pH}$, indicative of a $2 e^{-}, 3 \mathrm{H}^{+}$process. This superNernstian behavior often signifies that the redox transition is coupled with not only the deprotonation of a group adsorbed on the Co, but also with a more extended deprotonation of sites within the lattice with a $\mathrm{pKa}$ of approximately 12 , as at this $\mathrm{pH}$ value, the magnitude of the redox wave stops increasing ${ }^{26,32,33}$. On the other hand, the $\mathrm{Co}(\mathrm{III} / \mathrm{IV})$ redox wave shifted $63 \mathrm{mV} / \mathrm{pH}$, indicating that this process was a simple $1 e^{-}, 1 \mathrm{H}^{+}$(or $2 e^{-}, 2 \mathrm{H}^{+}$) process. The current necessary to attain $10 \mathrm{~mA} / \mathrm{cm}^{2}$, as measured in galvanostatic mode, showed a shift of $102 \mathrm{mV} / \mathrm{pH}$. Such a dependence of $\mathrm{pH}$ on OER catalysis has previously been attributed to a decoupling of proton transfer, electron transfer, and catalytic steps in the OER cycle and has often implied the active role of lattice oxygen in reaction pathway $^{34,35}$. The next measurement in the series was the use of chemical probes to deduce the presence of particular surface intermediates. We first introduced $1 \mathrm{M}$ methanol into the electrolyte as adsorbed nucleophilic $* \mathrm{OH}$ groups on metal oxide surfaces were previously found to react with alcohols ${ }^{36}$. Indeed, we observed a slow onset of methanol oxidation just past the Co(II/III) redox transition pointing to the initiation of reactive $* \mathrm{OH}$ coverage at this potential value (Fig. 4e). On the other hand, using $1 \mathrm{M}$ tetramethylammonium hydroxide (TMAOH) as the electrolyte, previously argued to specifically interact with active oxygen species and thus hinder the OER cycle ${ }^{37,38}$, shifted the $\mathrm{Co}(\mathrm{II} / \mathrm{III})$ redox peak and increased the Tafel slope to $34 \mathrm{mV} / \mathrm{dec}$. This provides evidence for interactions between the $\mathrm{Co}_{0.5} \mathrm{Fe}_{0.5} \mathrm{O}_{0.5} \mathrm{~F}_{1.5}$ surface and TMA ions, likely through activated oxygen species.

Finally, to probe chemical nature of the rate-limiting step in the OER cycle, we utilized H/D and ${ }^{16} \mathrm{O} /{ }^{18} \mathrm{O}$ isotope measurements. In comparing the $\mathrm{CV}$ measurements (Fig. 4f) and the resultant Tafel slopes (Fig. 4g), there were minimal changes between the catalyst in $\mathrm{KOH}$ and $\mathrm{KOD}$ electrolytes, implying that these species were not involved in the rate limiting step. However, when using $\mathrm{K}^{18} \mathrm{OH}$, the resultant current density dropped significantly and the Tafel slope increased by approximately $15 \mathrm{mV} / \mathrm{dec}$, to $42 \mathrm{mV} / \mathrm{dec}$ which indicates that oxygen atoms are the sole species involved in the rate limiting step and the catalytic cycle is pushed away from the conventional one with proton-coupled electron transfer (PCET) steps often involving the breaking of a O-H bond ${ }^{6}$. 
In a complementary thrust, in operando Raman spectroscopy was performed as this type of vibrational spectroscopy can help to elucidate changes in catalyst surface structure through the course of the reaction cycle (Fig. 4h). We focused on the spectral region of $100-900 \mathrm{~cm}^{-1}$, where M-M and M$\mathrm{O}$ vibrational modes are typically seen. While there is not an established literature base that can be used to unambiguously assign bands to the particular vibrational modes of $\mathrm{Co}_{0.5} \mathrm{Fe}_{0.5} \mathrm{O}_{0.5} \mathrm{~F}_{1.5}$, we probe the changes in the spectra and reference vs. previous Raman observations of OER-active cobalt and iron-based catalysts. At open circuit, bands at 342, 513, 620, 687, 735 and $809 \mathrm{~cm}^{-1}$ were observed. Upon the application of oxidizing potentials, the band at 513 redshifted to $501 \mathrm{~cm}^{-1}$, new band components arose at 590 and $580 \mathrm{~cm}^{-1}$, and a band at $687 \mathrm{~cm}^{-1}$ rose and fell. A band that progressively shifted from 609 to $580 \mathrm{~cm}^{-1}$ with positive potentials has previously been observed for $\mathrm{CoO}_{\mathrm{x}}$ thin films as Co underwent $\mathrm{Co}(\mathrm{II} / \mathrm{III})$ and $\mathrm{Co}(\mathrm{III} / \mathrm{IV})$ redox transitions ${ }^{39}$. A reasonable assignment would also be such changes in our spectra to Co-O species that are oxidized at $1.1 \mathrm{~V}$ and $1.4 \mathrm{~V}$. The emergence of a band at $503 \mathrm{~cm}^{-1}$ may also match that of $\mathrm{CoOOH}^{40,41}$. The potentials at which these changes occurred matched that of the $\mathrm{Co}(\mathrm{II} / \mathrm{III})$ and the $\mathrm{Co}(\mathrm{III} / \mathrm{IV})$ oxidations and onset of OER catalysis. In addition, the spectral features observed for $\mathrm{Co}_{0.5} \mathrm{Fe}_{0.5} \mathrm{O}_{0.5} \mathrm{~F}_{1.5}$ did not particularly match any spectra for iron oxide phases ${ }^{42,43}$. 
a

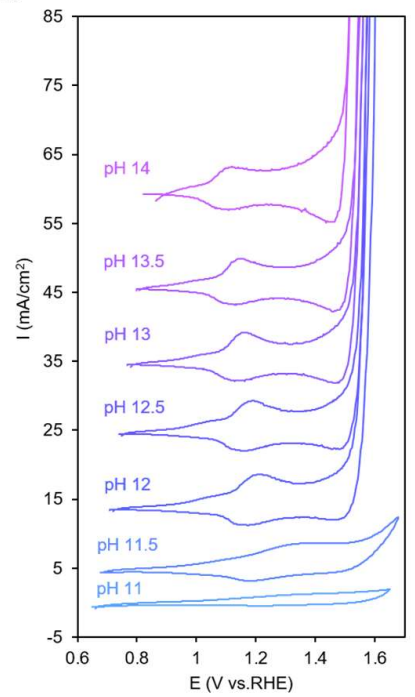

f

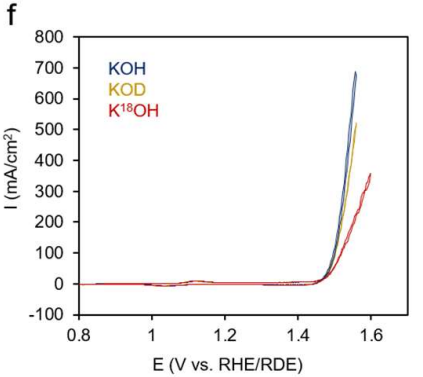

b
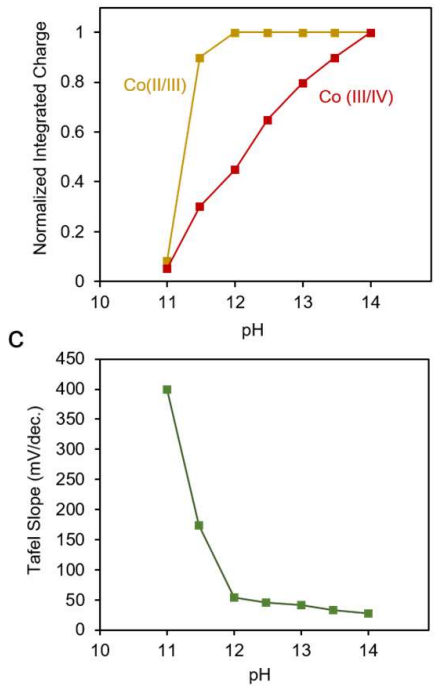

g

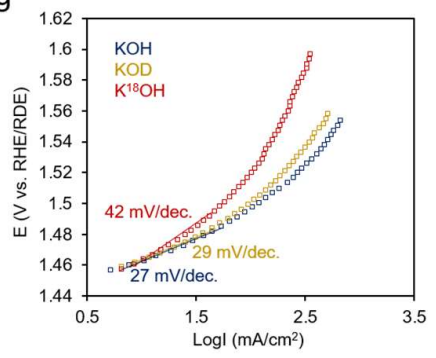

d
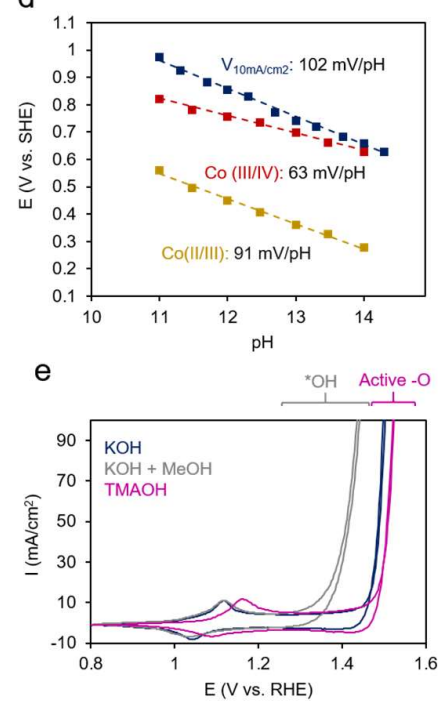

h

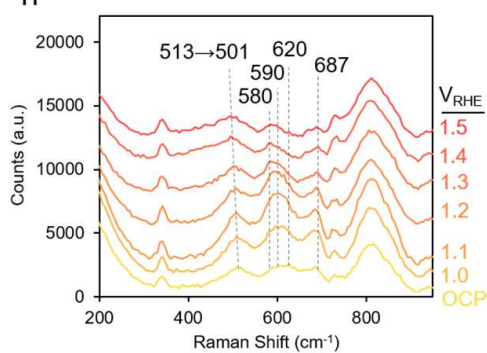

Figure 4: Analysis of the $\mathrm{CVs}$ of $\mathrm{Co}_{0.5} \mathrm{Fe}_{0.5} \mathrm{O}_{0.5} \mathrm{~F}_{1.5}$ at different $\mathrm{pH}$ electrolyte were used to unveil trends in Co redox and catalysis (a). As the pH increased, so did the quantity of Co(III) and Co(IV) observed (b). The increase in $\mathrm{pH}$ was coupled to an enhanced catalytic process, evidenced by the decrease in Tafel slope (c). Interestingly, the Co redox peaks and catalytic current exhibited both Nernstian and super-Nernstian $\mathrm{pH}$ shifts $(\mathbf{d}) .{ }^{*} \mathrm{OH}$ was evidenced above $1.1 \mathrm{~V}_{\mathrm{RHE}}$ through an increase in current in the presence of methanol while active oxygen species were evidenced when TMA cations were added to the electrolyte (e). Isotope measurements $(\mathbf{f}, \mathbf{g})$ indicated that the catalyst performance is most hampered by $\mathrm{K}^{18} \mathrm{OH}$ rather than KOD. Raman spectroscopy indicated hydration of $\mathrm{Co}_{0.5} \mathrm{Fe}_{0.5} \mathrm{O}_{0.5} \mathrm{~F}_{1.5}$ upon the application of positive potentials (h) shows three distinct species forming as a function of applied potential.

With above data in mind, we were able to construct a plausible mechanism for the OER on $\mathrm{Co}_{0.5} \mathrm{Fe}_{0.5} \mathrm{O}_{0.5} \mathrm{~F}_{1.5}$ surfaces (Fig. 5). First, a $2 e^{-}, 3 \mathrm{H}^{+}$process occurs at $1.1 \mathrm{~V}_{\mathrm{RHE}}$ to generate $\mathrm{Co}(\mathrm{III})$ and deprotonate adsorbed water groups to $* \mathrm{OH}$. Next, the $\mathrm{Co}(\mathrm{III})-\mathrm{OH}$ becomes further oxidized at $1.4 \mathrm{~V}_{\mathrm{RHE}}$ to $\mathrm{Co}(\mathrm{IV})-\mathrm{O}^{-}$, here illustrated as a $2 e^{-}, 2 \mathrm{H}^{+}$process. However, the presence of $\mathrm{Co}(\mathrm{IV})$ is not enough to achieve highly efficient OER catalysis as Co(IV) was observed even at $\mathrm{pH} 11$, in the absence of significant catalysis. Instead, there is another deprotonation step, likely that of a bridging oxygen atom, either between $\mathrm{Co}$ and $\mathrm{Co}$ or $\mathrm{Co}$ and $\mathrm{Fe}$. This deprotonation, along with the $2 e^{-}, 2 \mathrm{H}^{+} \mathrm{Co}$ (III/IV) transition give rise to the observed $102 \mathrm{mV} / \mathrm{pH}, 2 e^{-}, 3 \mathrm{H}^{+}$, rate dependence of the OER of 
$\mathrm{Co}_{0.5} \mathrm{Fe}_{0.5} \mathrm{O}_{0.5} \mathrm{~F}_{1.5}$ catalysts. The rapid drop in Tafel slope until $\mathrm{pH} 12$ indicates that the $\mathrm{pKa}$ of this bridging oxygen at $1.4 \mathrm{~V}_{\mathrm{RHE}}$ is approximately 12 .

Following the bridging oxygen deprotonation, is the $\mathrm{O}-\mathrm{O}$ bond formation, and finally the $\mathrm{O}_{2}$ release. The latter is the rate limiting step as evidenced through the computational efforts and $\mathrm{O}^{18}$ isotopic measurements. A plausible set of electron and water/hydroxide transfer steps was added finally to complete the OER cycle. Overall, the data implies a decoupling of key proton transfer, electron transfer and chemical steps and a lattice oxygen involving mechanism on $\mathrm{Co}_{0.5} \mathrm{Fe}_{0.5} \mathrm{O}_{0.5} \mathrm{~F}_{1.5}$, a departure from the conventional route of purely proton-coupled electron transfer steps, though one that is highly efficient. Further, the active site here is deemed to be a Co-Fe bimolecular site.

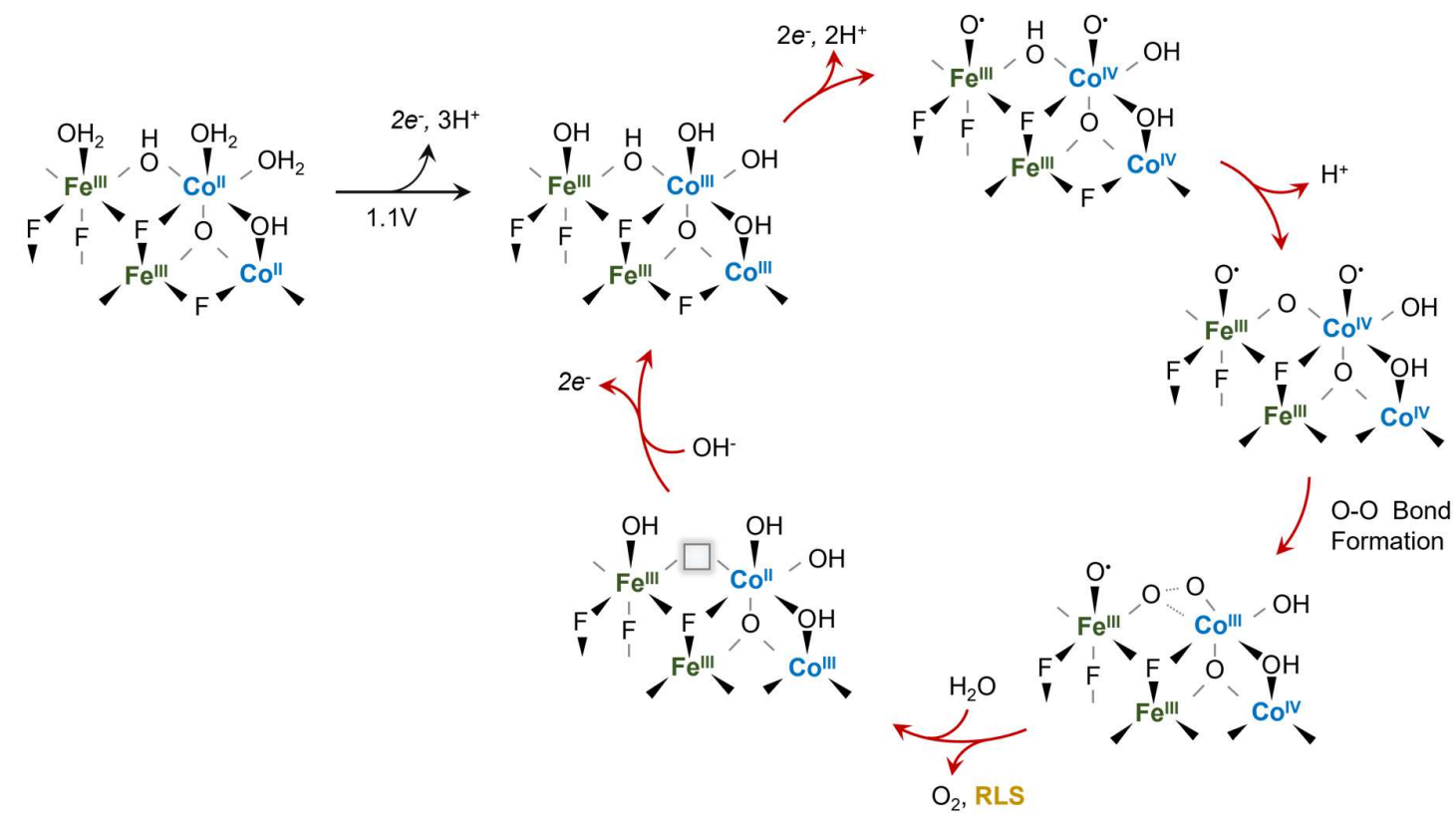

Figure 5: Proposed reaction pathway on $\mathrm{Co}_{0.5} \mathrm{Fe}_{0.5} \mathrm{O}_{0.5} \mathrm{~F}_{1.5}$ surfaces. Note: surface charges are omitted for simplicity.

Returning back to conventional limitations in OER catalysis, this mechanism, which circumvents the standard PCET route, appears to be the origin of the $\mathrm{Co}_{0.5} \mathrm{Fe}_{0.5} \mathrm{O}_{0.5} \mathrm{~F}_{1.5}$ exceptional performance. In fact, in recent years, key high performing alkaline OER catalysts also bypassed the standard PCET mechanism. ${ }^{27,32,35,37,44,45}$ While the exact nature of every step and free-energy landscape of the OER on different crystal facets and active sites is not yet elucidated, nor are the precise effects of the fluorine components on the $\mathrm{Co}$ and $\mathrm{Fe}$ species deciphered, there are many routes forward to take in understanding this system and building upon the extracted insights to design next-generation materials. Both soft and hard X-ray absorption spectroscopies would be key in capturing the elementspecific electronic changes throughout the catalytic cycle. Vibrational spectroscopy, especially with the aid of isotope labelling and time-resolved measurements would also be instrumental in detecting every intermediate in the reaction pathway to render a closer match between the proposed model and 
reality. In the direction of OER catalyst innovation, the exploration of novel anionic components substituted into transition metal oxides has shown to be a fruitful avenue to pursue and one can point to recently innovated oxyhalide catalysts. ${ }^{13,15,16,19}$

\section{Concluding Remarks}

The work put forth in this study highlights the utility of exploring hetero-anionic composition in the discovery of efficient catalytic materials. A mixed anion compound, $\mathrm{Co}_{0.5} \mathrm{Fe}_{0.5} \mathrm{O}_{0.5} \mathrm{~F}_{1.5}$, was fabricated through a controlled thermal conversion route and, the resultant material exhibited exceptionally high activity for the OER. A set of mechanistic investigations were carried out to elucidate key steps in the reaction mechanism and through this process, we found the OER proceeding through a super-Nernstian $\mathrm{pH}$-dependent process. In all, the research illustrated here is envisioned to open pathways in electrocatalyst design through the exploration of multi-metallic oxyfluoride materials that in key cases can surpass the activity of the state-of-the-art oxides. Mechanistically, exciting questions have yet to be answered, such as the elucidation of electronic structure changes and the precise interplay of $\mathrm{Co}, \mathrm{Fe}, \mathrm{F}$, and $\mathrm{O}$ components in the lattice, for which both theoretical modelling and X-ray absorption spectroscopy can potentially be instrumental. In the context of the OER, while $\mathrm{Co}_{0.5} \mathrm{Fe}_{0.5} \mathrm{O}_{0.5} \mathrm{~F}_{1.5}$ surpasses the performance of most known Co-based catalysts, there is no reason that it has to be the most active oxyfluoride. Thus, many promising avenues in nanostructuration, structural and compositional modulation may yield an even more active nextgeneration material.

\section{Acknowledgments:}

J.L. thanks CNRS for funding the EMERGENCE@INC2020 Project $\left(\mathrm{H}_{2} \mathrm{FLU}\right)$. The authors attached to IMMM gratefully acknowledge the users responsible of the technical platforms "X-ray Diffusion and Diffraction" and "Electron Microscopy" of IMMM (Le Mans University). N.K. acknowledges NSERC for its Discovery Grant RGPIN-2019-05927. All authors thank FRQNT Samuel de Champlain program, award 293526. A.S. acknowledges NSERC for its Discovery Grant RGPIN-2020-04960 and Canada Research Chair (950-23288). Computations in this research were enabled in part by support provided by Calcul Quebec and Compute Canada.

\section{References:}

1 Fawzy, S., Osman, A. I., Doran, J. \& Rooney, D. W. Strategies for mitigation of climate change: a review. Environ. Chem. Lett. 18, 2069-2094 (2020).

2 Stamenkovic, V. R., Strmcnik, D., Lopes, P. P. \& Markovic, N. M. Energy and fuels from electrochemical interfaces. Nat. Mater. 16, 57-69 (2017).

3 Montoya, J. H. et al. Materials for solar fuels and chemicals. Nat. Mater. 16, 70-81 (2017). 
Electrochemistry for a Sustainable World. Electrochem. Soc. Interface 29, 41-42 (2020).

Burke, M. S., Enman, L. J., Batchellor, A. S., Zou, S. \& Boettcher, S. W. Oxygen Evolution Reaction Electrocatalysis on Transition Metal Oxides and (Oxy)hydroxides: Activity Trends and Design Principles. Chem. Mater. 27, 7549-7558 (2015).

$\mathrm{Hu}, \mathrm{C}$., Zhang, L. \& Gong, J. Recent progress made in the mechanism comprehension and design of electrocatalysts for alkaline water splitting. Energy Environ. Sci. 12, 2620-2645 (2019).

7 Suen, N.-T. et al. Electrocatalysis for the oxygen evolution reaction: recent development and future perspectives. Chem. Soc. Rev. 46, 337-365 (2017).

8 Song, F. et al. Transition Metal Oxides as Electrocatalysts for the Oxygen Evolution Reaction in Alkaline Solutions: An Application-Inspired Renaissance. J. Am. Chem. Soc. 140, 77487759 (2018).

9 Song, J. et al. A review on fundamentals for designing oxygen evolution electrocatalysts. Chem. Soc. Rev. 49, 2196-2214 (2020).

10 Hunter, B. M., Gray, H. B. \& Müller, A. M. Earth-Abundant Heterogeneous Water Oxidation Catalysts. Chem. Rev. 116, 14120-14136 (2016).

11 Peugeot, A. et al. Benchmarking of oxygen evolution catalysts on porous nickel supports. Joule 5, 1281-1300 (2021).

12 Kuznetsov, D. A. et al. Tuning Redox Transitions via Inductive Effect in Metal Oxides and Complexes, and Implications in Oxygen Electrocatalysis. Joule 2, 225-244 (2018).

13 Lemoine, K. et al. Investigation of mixed-metal (oxy)fluorides as a new class of water oxidation electrocatalysts. Chem. Sci. 10, 9209-9218 (2019).

14 Liang, K. et al. Overall Water Splitting with Room-Temperature Synthesized NiFe Oxyfluoride Nanoporous Films. ACS Catal. 7, 8406-8412 (2017).

15 Fan, X. et al. Defect-enriched iron fluoride-oxide nanoporous thin films bifunctional catalyst for water splitting. Nat. Commun, 9, 1809 (2018).

16 Chen, P. et al. Dynamic Migration of Surface Fluorine Anions on Cobalt-Based Materials to Achieve Enhanced Oxygen Evolution Catalysis. Angew. Chem. Int. Ed. 57, 15471-15475 (2018).

17 Xue, Y. et al. Electrochemical oxygen evolution reaction catalyzed by a novel nickel-cobaltfluoride catalyst. Chem. Commun. 54, 6204-6207 (2018).

18 Han, H., Woo, J., Hong, Y.-R., Chung, Y.-C. \& Mhin, S. Polarized Electronic Configuration in Transition Metal-Fluoride Oxide Hollow Nanoprism for Highly Efficient and Robust Water Splitting. ACS Appl. Energy Mater. 2, 3999-4007 (2019).

19 Wang, J. et al. Redirecting dynamic surface restructuring of a layered transition metal oxide catalyst for superior water oxidation. Nat. Catal. 4, 212-222 (2021).

20 Huang, Z.-F. et al. Strategies to Break the Scaling Relation toward Enhanced Oxygen Electrocatalysis. Matter 1, 1494-1518 (2019).

21 Brink, F. J., Withers, R. L. \& Norén, L. Nonstoichiometric, Rutile-Type, Solid Solutions in the FeIIF2-FeIIIOF System. J. Solid State Chem. 161, 31-37 (2001).

22 Fan, X. et al. High energy-density and reversibility of iron fluoride cathode enabled via an intercalation-extrusion reaction. Nat. Commun, 9, 2324 (2018).

23 Zhou, H. et al. Formation of Iron Oxyfluoride Phase on the Surface of Nano-Fe3O4 Conversion Compound for Electrochemical Energy Storage. J. Phys. Chem. Lett. 4, 37983805 (2013).

24 Zhu, J. \& Deng, D. Wet-Chemical Synthesis of Phase-Pure FeOF Nanorods as High-Capacity Cathodes for Sodium-Ion Batteries. Angew. Chem. Int. Ed. 54, 3079-3083 (2015).

25 Lemoine, K. et al. New Amorphous Iron-Based Oxyfluorides as Cathode Materials for HighCapacity Lithium-Ion Batteries. J. Phys. Chem. C 123, 21386-21394 (2019).

26 Moysiadou, A., Lee, S., Hsu, C.-S., Chen, H. M. \& Hu, X. Mechanism of Oxygen Evolution Catalyzed by Cobalt Oxyhydroxide: Cobalt Superoxide Species as a Key Intermediate and Dioxygen Release as a Rate-Determining Step. J. Am. Chem. Soc. 142, 11901-11914 (2020).

27 Bergmann, A. et al. Reversible amorphization and the catalytically active state of crystalline Co3O4 during oxygen evolution. Nat. Commun, 6, 8625 (2015). 
Burke, M. S., Kast, M. G., Trotochaud, L., Smith, A. M. \& Boettcher, S. W. Cobalt-Iron (Oxy)hydroxide Oxygen Evolution Electrocatalysts: The Role of Structure and Composition on Activity, Stability, and Mechanism. J. Am. Chem. Soc. 137, 3638-3648 (2015).

$29 \mathrm{Zu}, \mathrm{C} . \mathrm{-X} . \& \mathrm{Li}, \mathrm{H}$. Thermodynamic analysis on energy densities of batteries. Energy Environ. Sci. 4, 2614-2624 (2011).

30 Hanaor, D. A. H., Xu, W., Ferry, M. \& Sorrell, C. C. Abnormal grain growth of rutile TiO2 induced by $\mathrm{ZrSiO} 4$. J. Cryst. Growth 359, 83-91 (2012).

31 Craig, M. J. et al. Universal scaling relations for the rational design of molecular water oxidation catalysts with near-zero overpotential. Nat. Commun, 10, 4993 (2019).

32 Bai, L., Lee, S. \& Hu, X. Spectroscopic and Electrokinetic Evidence for a Bifunctional Mechanism of the Oxygen Evolution Reaction**. Angew. Chem. Int. Ed. 60, 3095-3103 (2021).

33 Bediako, D. K., Surendranath, Y. \& Nocera, D. G. Mechanistic Studies of the Oxygen Evolution Reaction Mediated by a Nickel-Borate Thin Film Electrocatalyst. J. Am. Chem. Soc. 135, 3662-3674 (2013).

34 Grimaud, A. et al. Activating lattice oxygen redox reactions in metal oxides to catalyse oxygen evolution. Nat. Chem. 9, 457-465 (2017).

35 Zhang, N. et al. Lattice oxygen activation enabled by high-valence metal sites for enhanced water oxidation. Nat. Commun, 11, 4066 (2020).

36 Tao, H. B. et al. A General Method to Probe Oxygen Evolution Intermediates at Operating Conditions. Joule 3, 1498-1509 (2019).

37 Huang, Z.-F. et al. Chemical and structural origin of lattice oxygen oxidation in Co-Zn oxyhydroxide oxygen evolution electrocatalysts. Nat. Energy 4, 329-338 (2019).

38 Yang, C., Fontaine, O., Tarascon, J.-M. \& Grimaud, A. Chemical Recognition of Active Oxygen Species on the Surface of Oxygen Evolution Reaction Electrocatalysts. Angew. Chem. Int. Ed. 56, 8652-8656 (2017).

39 Yeo, B. S. \& Bell, A. T. Enhanced Activity of Gold-Supported Cobalt Oxide for the Electrochemical Evolution of Oxygen. J. Am. Chem. Soc. 133, 5587-5593 (2011).

40 Alrehaily, L. M., Joseph, J. M., Biesinger, M. C., Guzonas, D. A. \& Wren, J. C. Gammaradiolysis-assisted cobalt oxide nanoparticle formation. Phys. Chem. Chem. Phys. 15, 10141024 (2013).

41 Yang, J., Liu, H., Martens, W. N. \& Frost, R. L. Synthesis and Characterization of Cobalt Hydroxide, Cobalt Oxyhydroxide, and Cobalt Oxide Nanodiscs. J. Phys. Chem. C 114, 111119 (2010).

42 Bersani, D., Lottici, P. P. \& Montenero, A. Micro-Raman investigation of iron oxide films and powders produced by sol-gel syntheses. J. Raman Spectrosc. 30, 355-360 (1999).

43 de Faria, D. L. A., Venâncio Silva, S. \& de Oliveira, M. T. Raman microspectroscopy of some iron oxides and oxyhydroxides. J. Raman Spectrosc. 28, 873-878 (1997).

44 Grimaud, A., Hong, W. T., Shao-Horn, Y. \& Tarascon, J. M. Anionic redox processes for electrochemical devices. Nat. Mater. 15, 121-126 (2016).

45 Zhang, N. \& Chai, Y. Lattice oxygen redox chemistry in solid-state electrocatalysts for water oxidation. Energy Environ. Sci. (2021). 


\title{
Supporting Information
}

\section{Highly efficient water oxidation via a bimolecular reaction mechanism on rutile structured mixed-metal oxyfluorides}

\author{
Zahra Gohari-Bajestani, ${ }^{1}$ Xiao Wang, ${ }^{2}$ Amandine Guiet, ${ }^{1}$ Romain Moury, ${ }^{1}$ Jean-Marc Grenèche, ${ }^{1}$ \\ Annie Hémon-Ribaud, ${ }^{1}$ Yuxuan Zhang, ${ }^{3}$ Daniel Chartrand, ${ }^{3}$ Vincent Maisonneuve, ${ }^{1}$ Ali \\ Seifitokaldani, ${ }^{2 *}$ Nikolay Kornienko, ${ }^{3 *}$ Jérôme Lhoste ${ }^{1^{*}}$
}

${ }^{1}$ Institut des Molécules et Matériaux du Mans (IMMM), UMR 6283 CNRS, Le Mans Université, Avenue Olivier Messiaen, 72085 Le Mans Cedex 9, France

${ }^{2}$ Department of Chemical Engineering, McGill University, 3610 University Street, Montreal, Quebec H3A 0C5, Canada

${ }^{3}$ Department of Chemistry, Université de Montréal, 1375 Ave. Thérèse-Lavoie-Roux, Montréal, Québec, H2V 0B3, Canada

Equal Contribution

*corresponding authors: jerome.lhoste@univ-lemans.fr, nikolay.kornienko@umontreal.ca, and

ali.seifitokaldani@mcgill.ca

\section{Materials and methods}

\subsection{Synthesis}

$\mathrm{Fe}\left(\mathrm{NO}_{3}\right)_{3} .9 \mathrm{H}_{2} \mathrm{O}\left(99.0 \%\right.$, Alfa Aesar), $\mathrm{CoCl}_{2} \cdot 6 \mathrm{H}_{2} \mathrm{O}$ (99.5\%, Acros Organics), and hydrofluoric acid solution (27,9 mol.L ${ }^{-1}$, HF $48 \mathrm{wt} \%$, Honeywell) were used as received.

$\mathrm{CoFeF}_{5}\left(\mathrm{H}_{2} \mathrm{O}\right)_{7}$ was synthesized by coprecipitation in a hydrofluoric acid solution. The metal precursors, $\mathrm{Fe}\left(\mathrm{NO}_{3}\right)_{3} \cdot 9 \mathrm{H}_{2} \mathrm{O}(0.001 \mathrm{~mol})$ and $\mathrm{CoCl}_{2} \cdot 6 \mathrm{H}_{2} \mathrm{O}(0.001 \mathrm{~mol})$, were dissolved into $10 \mathrm{~mL}$ of aqueous $\mathrm{HF}_{48 \%}$. The reaction mixture was placed in a Teflon Becher and stirred for $1 \mathrm{~h}$ at $100^{\circ} \mathrm{C}$ until the formation of a precipitate. After cooling, the mixture was filtered, washed with ethanol and dried 
at room temperature giving pink micro-crystalline powder $\mathrm{CoFeF}_{5}\left(\mathrm{H}_{2} \mathrm{O}\right)_{7} . \mathrm{Co}^{2+} \mathrm{Fe}^{3+} \mathrm{O}_{0.5} \mathrm{~F}_{1.5}$ is obtained by the thermal treatment of $\mathrm{Co}^{2+} \mathrm{Fe}^{3+} \mathrm{F}_{5}\left(\mathrm{H}_{2} \mathrm{O}\right)_{7}$ under ambient atmosphere at $240^{\circ} \mathrm{C}$ for $1 \mathrm{~h}$ in a muffle furnace corresponding to an experimental weight loss of $43.4 \%$ close to the theoretical value $43.9 \%$ $\left(\mathrm{m}_{\text {before }}=175 \mathrm{mg}, \mathrm{m}_{\mathrm{after}}=99 \mathrm{mg}\right)$.

\section{Characterization methods}

X-ray diffraction patterns were collected in the range $10^{\circ} \leq 2 \theta \leq 150^{\circ}$ on a Panalytical MPD-PRO diffractometer equipped with a linear X'celerator detector with $\mathrm{CuK} \alpha(1.5406 \AA)$ anode. Rietveld refinements were performed by using the Fullprof profile refinement program.

X-ray thermodiffraction (HT-XRD) was performed under ambient air in an Anton Parr XRK 900 high temperature furnace with diffractometer described. The samples were heated from 40 to $600^{\circ} \mathrm{C}$ at a heating rate of $10^{\circ} \mathrm{C} \cdot \mathrm{min}^{-1}$. X-ray diffraction patterns were recorded in the $\left[5-60^{\circ}\right] 2 \theta$ range with a scan time of $10 \mathrm{~min}$ at $20^{\circ} \mathrm{C}$ intervals from room temperature to 400 and at $100^{\circ} \mathrm{C}$ intervals from 400 to $600^{\circ} \mathrm{C}$.

Mass Spectroscopy coupled Thermo Gravimetric Analysis (MS-TGA) was performed using a Netzch STA 449 F3 coupled with a QMS 403 C mass spectrometer. The thermoanalytical curves were recorded from room temperature up to $500^{\circ} \mathrm{C}$ together with the ion current curves in the multiple ions detection probe. A constant purge nitrogen gas flow of $80 \mathrm{~mL} \cdot \mathrm{min}^{-1}$ and a constant heating rate of $3^{\circ} \mathrm{C} \cdot \mathrm{min}^{-1}$ were applied. The thermogravimetric (TGA) experiments under dry air (Alphagaz, mixture of oxygen $(20 \%)$ with nitrogen $\left.(80 \%), \mathrm{H}_{2} \mathrm{O}<3 \mathrm{ppm}\right)$ or ambient air were carried out with a thermoanalyzer SETARAM TGA 92 with a heating rate of $3^{\circ} \mathrm{C} \cdot \mathrm{min}^{-1}$ from room temperature up to $600^{\circ} \mathrm{C}$.

SEM images were obtained using a JEOL microscope (JSM 6510 LV). Acceleration voltages varied between $20 \mathrm{kV}$ as a function of the analyzed samples. Elementary quantitative microanalyses were performed using an Energy Dispersive X-ray (EDX) OXFORD detector (AZtec software).

The TEM was conducted on a JEOL JEM $2100 \mathrm{HR}$ electron microscope operating at $200 \mathrm{kV}$ and equipped with a single-tilt specimen holder. The sample for transmission electron microscopy investigation were prepared by ultrasonically dispersing the raw powder in ethanol, depositing a drop of the resulting suspension onto a holey carbon-coated copper grid, and finally drying the grid in air. 
Mössbauer measurements were performed in transmission geometry with a $925 \mathrm{MBq} \gamma$-source of $57 \mathrm{Co} / \mathrm{Rh}$ mounted on a conventional constant acceleration drive. The samples with $5 \mathrm{mg} \mathrm{of} \mathrm{Fe} \cdot \mathrm{cm}^{-2}$ were prepared from a softly milled powder. Data were fitted using the MOSFIT program ${ }^{46}$ involving quadrupolar and/or magnetic components with Lorentzian lines; the isomer shift values are referred to that of $\alpha$-Fe at RT. The velocity of the source was calibrated using $\alpha-\mathrm{Fe}$ as the standard at room temperature.

Infrared spectra were collected at room temperature on a FT-IR ALPHA Bruker Optik spectrometer (single reflection diamond) over the range 400-4000 $\mathrm{cm}^{-1}$. Electrochemical measurements were conducted through a Biologic SP200 potentiostat and EC-lab software. $\mathrm{Hg} / \mathrm{HgO}$ reference and Pt foil or carbon rod counter electrodes were employed for the measurements. Custom-built one and two compartment glass electrochemical cells were employed and purified KOH (or KOD) was used as the electrolyte. Working electrodes were either glass carbon rotating disks or Toray carbon paper. A catalyst ink was prepared by sonicating typically $5 \mathrm{mg}$ and $0.1 \mathrm{mg}$ of carbon nanotubes of the catalyst in 2:1 ethanol: water $(\mathrm{V}: \mathrm{V})$. The ink was dropped cast onto the working electrodes and allowed to dry under ambient conditions for 20 minutes prior to use. Catalyst loadings were $1 \mathrm{mg} / \mathrm{cm}^{2}$ on the carbon paper and $0.1 \mathrm{mg} / \mathrm{cm}^{2}$ on the glassy carbon working electrodes. Prior to electrochemical measurements, the impedance between reference and working electrode was recorded at open circuit and ohmic drop was subsequently corrected for at 95\% with the ZIR function in the EC-lab software.

Operando Raman spectroscopy was conducted in a similar fashion as mentioned above, except a $\mathrm{Ag} / \mathrm{AgCl}$ reference electrode was employed, and a custom-built Teflon spectroelectrochemical cell was used. An immersion objective was chosen to obtain the highest intensities, and measurements at each potential were recorded over a period of 5 minutes to attain a steady-state spectrum. A Renishaw Invia spectrometer was used with a $514 \mathrm{~nm}$ laser for these experiments.

Density functional theory (DFT) calculations were carried out by utilizing the Gaussian Plane Waves method (GPW) in the Quickstep module of the CP2K software package. ${ }^{47}$ Goedecker-Teter-Hutter (GTH) pseudopotentials ${ }^{48}$ with an energy cutoff of 450 Ry were employed in all simulations. The optimization of different systems and structures deployed the double- $\zeta$ shorter-range (DZVPMOLOPT-SR-GTH) basis set optimized in molecular calculations ${ }^{49}$ and the Perdew-Burke-Ernzerhof (PBE) exchange-correlation functional within the generalized gradient approximation (GGA). ${ }^{50}$ To capture Van der Waals interactions, we harnessed the DFT-D3 dispersion correction method by Grimme et al. ${ }^{51}$ A $5 \times 4 \times 2$ Monkhorst-Pack k-point mesh was utilized to accomplish Brillouin zone integration.

To build the models for $\mathrm{Co}_{0.5} \mathrm{Fe}_{0.5} \mathrm{O}_{0.5} \mathrm{~F}_{1.5}$, we chose two possible structures to determine the roles of $\mathrm{Co}$ and $\mathrm{Fe}$ atoms, where the interchange between $\mathrm{Co}$ and $\mathrm{Fe}$ atoms takes place intermittently 
$(\mathrm{CoFeOF}(110)-1)$ or continuously $(\mathrm{CoFeOF}(110)-2)$. (110) facets were chosen since they were reported to be the most stable surface in rutile structures. ${ }^{24,30}$ After the primitive unit cell was optimized through cell optimization, we employed the Atomic Simulation Environment (ASE) codes to create the slabs containing $10 \AA$ of vacuum above and below the atoms (i.e. $20 \AA$ of vacuum in total) for geometry optimization. ${ }^{52}$ For both cell and geometry optimizations, the convergence criteria for the maximum force acting on each atom were set to be $0.023 \mathrm{eV} / \AA$, and the BFGS method was used as the optimizers. An applied potential $(U)$ to the system changes the energy of one electron by $e U$, where $e$ is the electron charge ${ }^{53}$.

The Bader charge analysis was performed using the Bader analysis program written by Henkelman et al. ${ }^{52,54-56}$ Meanwhile, the charge density plots were generated from the cube files containing the electronic density with the help of the cube cruncher utility within CP2K's tool-collection.

The adsorption energy of $\mathrm{O}_{2}\left(\mathrm{E}_{\text {ads }}\right)$ was calculated by using the following equation ${ }^{53}$,

$\mathrm{E}_{\mathrm{ads}}=\mathrm{E}\left(\right.$ slabs $\left.+\mathrm{O}_{2}\right)-\mathrm{E}($ slabs $)-\mathrm{E}\left(\mathrm{O}_{2}\right)$

where $\mathrm{E}\left(\right.$ slabs $\left.+\mathrm{O}_{2}\right), \mathrm{E}\left(\right.$ slabs), and $\mathrm{E}\left(\mathrm{O}_{2}\right)$ represent the total energy of the slabs with $\mathrm{O}_{2}$ adsorbed on it, slabs, and $\mathrm{O}_{2}$, respectively.

\section{Synthetic approach}

The new Co-Fe based oxyfluoride with rutile structure was prepared by thermal decomposition of the corresponding crystalline hydrated phase $\left(\mathrm{CoFeF}_{5}\left(\mathrm{H}_{2} \mathrm{O}\right)_{7}\right)$. A first attempt to synthesize the precursor $\mathrm{CoFeF}_{5}\left(\mathrm{H}_{2} \mathrm{O}\right)_{7}$ was performed using solvothermal synthesis leading to a multiphase system with $\mathrm{CoFe}_{2} \mathrm{~F}_{8}\left(\mathrm{H}_{2} \mathrm{O}\right)_{2}$ as an impurity (Figure S1). While the XRD patterns of $\mathrm{MFeF}_{5}\left(\mathrm{H}_{2} \mathrm{O}\right)_{7}(\mathrm{M}=\mathrm{Fe}, \mathrm{Co}, \mathrm{Ni})$ exist in the crystallographic database, their structures are unresolved. In our preparation, single crystals have been isolated and two new structures of hydrated fluorides phase, with the same formulation $\mathrm{CoFeF}_{5}\left(\mathrm{H}_{2} \mathrm{O}\right)_{7}$ were solved using single crystal X-ray diffraction. The first one was determined in the triclinic $P-1$ space group, and the second one was in the monoclinic $C 2 / \mathrm{m}$ space group. The details of the structure determination and the X-ray atomic coordinates are summarized in Table S1-S7. Both polymorphs are built up from isolated $\left(\mathrm{FeF}_{5}\left(\mathrm{H}_{2} \mathrm{O}\right)\right)^{2-}$ anions hydrogen linked to $\left(\mathrm{Co}\left(\mathrm{H}_{2} \mathrm{O}\right)_{6}\right)^{2+}$ through hydrogen bonds with $\mathrm{Co}^{2+}$ and $\mathrm{Fe}^{3+}$ cations sitting on the $48 h$ Wyckoff positions. The iron octahedra exhibit four similar Fe-F distances (1.90-1.93 $\AA$ ) in the equatorial plane and two slightly longer distances (1.97-2.02 $\AA$ ) associated to statically occupation of fluorine atoms and water molecules on the apical positions with a $\mathrm{F} / \mathrm{O}$ disorder equal to $0.5 / 0.5$. Bond-valence calculations confirmed the metal cations sites and the positions of the oxygen and fluorine atoms. The $\mathrm{Co}\left(\mathrm{H}_{2} \mathrm{O}\right)_{6}$ octahedra are more regular $(2.05-2.10 \AA)$ and are hydrogen bonded to $\mathrm{FeF}_{5}\left(\mathrm{H}_{2} \mathrm{O}\right)$ octahedra with $\mathrm{O}-\mathrm{H} \cdots \mathrm{F}$ distances ranging from $2.63 \AA$ to $3.07 \AA$ (Table S8 and Table S9). 
The crystal structure of pink crystalline $\mathrm{CoFeF}_{5}\left(\mathrm{H}_{2} \mathrm{O}\right)_{7}$ was determined by single crystal X-ray diffraction (Fig. S1 and Table S1-S7), and Rietveld refinement (Fig. S3 and Table S8-S10) of the powder X-ray diffraction pattern (PXRD) confirmed the phase purity. Scanning Electron Microscopy (SEM, Fig. S7b) revealed the formation of $\mathrm{CoFeF}_{5}\left(\mathrm{H}_{2} \mathrm{O}\right)_{7}$ micro-sized particles which is in good accordance with the sharpness of the peaks in the diffraction pattern and a specific surface area $\left(\mathrm{S}_{\mathrm{BET}}\right.$ determined by $\mathrm{N}_{2}$ sorption) less than $3 \mathrm{~m}^{2} \mathrm{~g}^{-1}$. The homogenous distribution of $\mathrm{Co}, \mathrm{Fe}, \mathrm{O}$ and $\mathrm{F}$ and the $\mathrm{Fe} / \mathrm{Co}$ atomic ratio of 1 in the material is confirmed by elemental mapping, obtained by SEM coupled Energy Dispersive Spectroscopy (EDS-SEM, Fig. S7a). ${ }^{57} \mathrm{Fe}$ Mössbauer experiments were carried out to gain insight into the iron chemical environment and the valence states. The Mössbauer spectra obtained at $300 \mathrm{~K}$ and $77 \mathrm{~K}$ consist of broadened and asymmetrical quadrupolar doublets. The refined values of the hyperfine parameters indicate unambiguously the presence of high spin $\mathrm{Fe}^{3+}$ species in octahedral coordination (Table S11). To correlate the hyperfine parameters, we considered anionic disorder as $\mathrm{F}-\mathrm{O}$ disorders in the $\mathrm{Fe}^{3+}$ environment can lead to three possible octahedral configurations: $\mathrm{FeF}_{6}, \mathrm{FeF}_{5}\left(\mathrm{H}_{2} \mathrm{O}\right)$ and $\mathrm{FeF}_{4}\left(\mathrm{H}_{2} \mathrm{O}\right)_{2}$ with the respective proportions 25:50:25. The hydrogen directions are slightly different between the two structures leading to a tilting of octahedra and change structure (Figure S2). The evolution of the composition was also confirmed by FTIR, PXRD and followed by color change from pink to brown (Fig. S4-S6). These results confirmed unambiguously the formation of $\mathrm{Co}_{0.5} \mathrm{Fe}_{0.5} \mathrm{O}_{0.5} \mathrm{~F}_{1.5}$ with rutile structure type. The lattice parameters follow a good approximation to Vegard's law of $\mathrm{CoF}_{2}$ (ICSD-280604, V=70.1 $\AA^{3}$ ) / FeOF (ICSD-2875, V=66.2 $\AA^{3}$ ) system confirming the formulation of the oxyfluoride $\mathrm{Co}^{2+}{ }_{0.5} \mathrm{Fe}^{3+}{ }_{0.5} \mathrm{O}_{0.5} \mathrm{~F}_{1.5}$ (Fig. S8) 


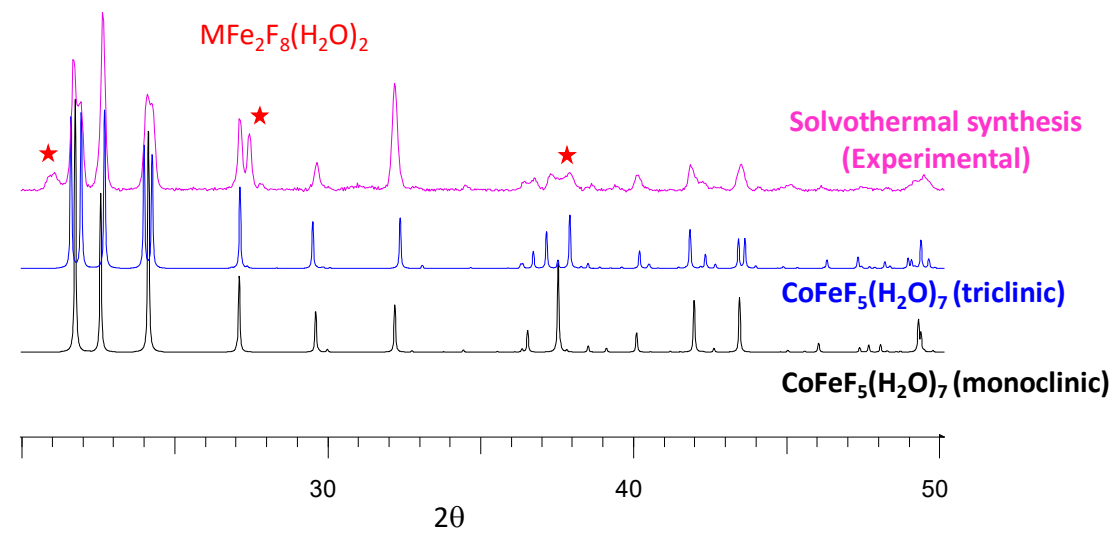

Figure S1. Experimental PXRD pattern of powder obtained from solvothermal synthesis (pink) and simulated XRD patterns of $\mathrm{CoFeF}_{5}\left(\mathrm{H}_{2} \mathrm{O}\right)_{7}$ determined in triclinic (blue) and monoclinic (black) systems.

Table S1: Crystal data* and structure of $\mathrm{CoFeF}_{5}\left(\mathrm{H}_{2} \mathrm{O}\right)_{7}$ in triclinic and monoclinic systems and refinement parameters obtained from powder XRD.

\begin{tabular}{|c|c|c|c|}
\hline \multirow{2}{*}{$\begin{array}{l}\text { Compounds } \\
\text { Data }\end{array}$} & \multicolumn{2}{|c|}{$\mathrm{t}-\mathrm{CoFeF}_{5}\left(\mathrm{H}_{2} \mathrm{O}\right)_{7}$} & \multirow{2}{*}{$\frac{\mathbf{m}-\mathrm{CoFeF}_{\mathbf{5}}\left(\mathrm{H}_{\mathbf{2}} \mathrm{O}\right)_{7}}{\text { Crystal }}$} \\
\hline & Crystal & Powder & \\
\hline Molecular weight $\left(\mathrm{g} \cdot \mathrm{mol}^{-1}\right)$ & \multicolumn{2}{|c|}{335.9} & 335.9 \\
\hline Crystal system & \multicolumn{2}{|c|}{ triclinic } & monoclinic \\
\hline Space group & \multicolumn{2}{|c|}{$P-1$} & $C 2 / m$ \\
\hline $\mathrm{a}(\AA)$ & $6.5241(5)$ & $6.5378(3)$ & $11.000(1)$ \\
\hline $\mathrm{b}(\AA)$ & $8.8575(7)$ & $8.8458(4)$ & $14.010(1)$ \\
\hline $\mathrm{c}(\AA)$ & $8.9788(7)$ & $8.9730(4)$ & $6.563(1)$ \\
\hline$\alpha\left(^{\circ}\right)$ & $104.025(4)$ & $103.956(10)$ & 90 \\
\hline$\beta\left(^{\circ}\right)$ & $96.993(4)$ & $97.0324(9)$ & $100.441(3)$ \\
\hline$\gamma\left({ }^{\circ}\right)$ & $95.479(4)$ & $95.5055(9)$ & 90 \\
\hline $\mathrm{V}\left(\AA^{3}\right)$ & $495.42(7)$ & $495.55(4)$ & $994.7(2)$ \\
\hline $\mathrm{Z}, \rho_{\text {calc. }}\left(\mathrm{g} \mathrm{cm}^{-3}\right)$ & $2,2.238$ & $2,2.252$ & $4,2.229$ \\
\hline Wavelength $(\AA)$ & $\mathrm{MoK}_{\alpha}$ & $\mathrm{CoK}_{\alpha}$ & $\mathrm{MoK}_{\alpha}$ \\
\hline$\mu / \mathrm{mm}^{-1}$ & 3.227 & - & 3.214 \\
\hline $2 \theta$ range $\left(^{\circ}\right)$ & $4.7-55.0$ & $5.0-120.0$ & $4.8-60.2$ \\
\hline Limiting indices & $\begin{aligned}-8 & \leq \mathrm{h} \leq 8 \\
-11 & \leq \mathrm{k} \leq 11 \\
-11 & \leq 1 \leq 11\end{aligned}$ & $\begin{array}{l}- \\
- \\
-\end{array}$ & $\begin{aligned}-15 & \leq \mathrm{h} \leq 15 \\
-19 & \leq \mathrm{k} \leq 19 \\
-9 & \leq 1 \leq 9\end{aligned}$ \\
\hline Collected reflections & 17280 & & 8781 \\
\hline Unique reflections & 2286 & 2083 & 1528 \\
\hline Refined parameters & 169 & 69 & 92 \\
\hline Goodness-of-fit on $\mathrm{F}^{2}$ & 1.045 & - & 1.092 \\
\hline Final $\mathrm{R}$ indices $[\mathrm{I}>2 \sigma(\mathrm{I})]$ & $\begin{array}{l}\mathrm{R}_{1}=0.0366 \\
\mathrm{R}_{\mathrm{w} 1}=0.0875\end{array}$ & - & $\begin{array}{c}\mathrm{R}_{1}=0.0425 \\
\mathrm{Rw}_{1}=0.1026\end{array}$ \\
\hline $\mathrm{R}$ indices (all data) & $\begin{array}{l}\mathrm{R}_{1}=0.0507 \\
\mathrm{R}_{\mathrm{w} 1}=0.0933\end{array}$ & $\begin{array}{l}- \\
-\end{array}$ & $\begin{array}{c}\mathrm{R}_{1}=0.0792 \\
\mathrm{Rw}_{1}=0.1167\end{array}$ \\
\hline $\mathrm{R}_{\mathrm{p}} / \mathrm{R}_{\mathrm{wp}}$ & - & $0.0821 / 0.0592$ & - \\
\hline
\end{tabular}




\begin{tabular}{|l|c|c|c|}
\hline $\mathrm{R}_{\mathrm{B}} / \mathrm{R}_{\mathrm{f}}$ & - & $0.0287 / 0.0428$ & - \\
\hline $\begin{array}{l}\text { Largest diff. peak and } \\
\text { hole/e. } \AA^{-3}\end{array}$ & $0.666 /-0.452$ & - & $0.760 /-0.705$ \\
\hline
\end{tabular}

*Crystals were selected under polarizing optical microscope and mounted on MicroMount needles (MiTiGen) for single-crystal X-ray diffraction experiments. X-ray intensity data were collected on a Bruker APEX II Quazar diffractometer (4 circle Kappa goniometer, CCD detector) using I $\mu$ s microfocus source (Mo- $K_{\alpha}$ radiation with $\lambda=0.71073 \AA$ ) at $296 \mathrm{~K}$. The structure solutions were obtained by direct methods, developed by successive difference Fourier syntheses, and refined by fullmatrix least-squares on all $\mathrm{F}^{2}$ data using SHELX program suite in Bruker APEX2 interface.

Table S2: Atomic coordinates and equivalent isotropic displacement parameters in triclinic system.

\begin{tabular}{|c|c|c|c|c|c|l|}
\hline Atom & site & $\mathbf{x}$ & $\mathbf{y}$ & $\mathbf{z}$ & $\boldsymbol{\tau}$ & $\mathbf{B}_{\mathrm{eq}}\left(\AA^{2}\right)$ \\
\hline $\mathrm{Co}(1)$ & $2 \mathrm{~d}$ & $1 / 2$ & $1 / 2$ & 1 & 1 & $1.32(2)$ \\
$\mathrm{Co}(2)$ & $2 \mathrm{~d}$ & $1 / 2$ & 0 & $1 / 2$ & 1 & $1.43(2)$ \\
$\mathrm{Fe}(1)$ & $2 \mathrm{~d}$ & 1 & 1 & 1 & 1 & $1.34(2)$ \\
$\mathrm{Fe}(2)$ & 2d & 1 & $1 / 2$ & Approx.0.500000 & 1 & $1.41(2)$ \\
$\mathrm{F}(1)$ & $1 \mathrm{~d}$ & $1.1116(5)$ & $0.9302(3)$ & $0.8038(3)$ & 0.5 & $3.02(6)$ \\
$\mathrm{O}(1)$ & $1 \mathrm{~d}$ & $1.1116(5)$ & $0.9302(3)$ & $0.8038(3)$ & 0.5 & $3.02(6)$ \\
$\mathrm{F}(2)$ & $1 \mathrm{~d}$ & $0.9542(4)$ & $0.7287(3)$ & $0.5398(4)$ & 0.5 & $3.22(6)$ \\
$\mathrm{O}(2)$ & $1 \mathrm{~d}$ & $0.9542(4)$ & $0.7287(3)$ & $0.5398(4)$ & 0.5 & $3.22(6)$ \\
$\mathrm{F}(3)$ & $1 \mathrm{~d}$ & $0.9229(4)$ & $1.1832(3)$ & $0.9381(3)$ & 1 & $2.57(6)$ \\
$\mathrm{F}(4)$ & $1 \mathrm{~d}$ & $0.7323(4)$ & $0.8917(3)$ & $0.9036(3)$ & 1 & $2.76(5)$ \\
$\mathrm{F}(5)$ & $1 \mathrm{~d}$ & $0.7129(3)$ & $0.4355(3)$ & $0.4197(3)$ & 1 & $2.52(5)$ \\
$\mathrm{F}(6)$ & $1 \mathrm{~d}$ & $1.0592(4)$ & $0.5070(4)$ & $0.2994(3)$ & 1 & $3.43(6)$ \\
$\mathrm{O}(3)$ & $1 \mathrm{~d}$ & $0.8112(4)$ & $0.5713(4)$ & $1.0758(4)$ & 1 & $2.62(6)$ \\
$\mathrm{H}(3) \mathrm{A}$ & $1 \mathrm{~d}$ & $0.892(4)$ & $0.647(2)$ & $1.051(3)$ & 1 & 3.16 \\
$\mathrm{H}(3) \mathrm{B}$ & $1 \mathrm{~d}$ & $0.894(4)$ & $0.539(3)$ & $1.146(3)$ & 1 & 3.16 \\
$\mathrm{O}(4)$ & $1 \mathrm{~d}$ & $0.4516(5)$ & $0.7306(3)$ & $1.0115(4)$ & 1 & $2.64(6)$ \\
$\mathrm{H}(4) \mathrm{A}$ & $1 \mathrm{~d}$ & $0.3221(19)$ & $0.758(4)$ & $1.007(4)$ & 1 & 3.16 \\
$\mathrm{H}(4) \mathrm{B}$ & $1 \mathrm{~d}$ & $0.524(3)$ & $0.797(3)$ & $0.970(3)$ & 1 & 3.16 \\
$\mathrm{O}(5)$ & $1 \mathrm{~d}$ & $0.5528(4)$ & $0.4612(4)$ & $0.7695(3)$ & 1 & $2.30(5)$ \\
$\mathrm{H}(5) \mathrm{A}$ & $1 \mathrm{~d}$ & $0.470(3)$ & $0.502(4)$ & $0.706(3)$ & 1 & 2.76 \\
$\mathrm{H}(5) \mathrm{B}$ & $1 \mathrm{~d}$ & $0.678(2)$ & $0.467(5)$ & $0.738(3)$ & 1 & 2.76 \\
$\mathrm{O}(6)$ & $1 \mathrm{~d}$ & $0.2200(5)$ & $-0.1238(4)$ & $0.3727(3)$ & 1 & $2.65(6)$ \\
$\mathrm{H}(6) \mathrm{A}$ & $1 \mathrm{~d}$ & $0.127(4)$ & $-0.181(3)$ & $0.410(3)$ & 1 & 3.16 \\
$\mathrm{H}(6) \mathrm{B}$ & $1 \mathrm{~d}$ & $0.167(4)$ & $-0.136(4)$ & $0.2724(13)$ & 1 & 3.16 \\
$\mathrm{O}(7)$ & $1 \mathrm{~d}$ & $0.3298(5)$ & $0.1245(4)$ & $0.6611(4)$ & 1 & $3.61(8)$ \\
$\mathrm{H}(7) \mathrm{A}$ & $1 \mathrm{~d}$ & $0.2814(11)$ & $0.1793(8)$ & $0.5950(5)$ & 1 & 4.34 \\
$\mathrm{H}(7) \mathrm{B}$ & $1 \mathrm{~d}$ & $0.4117(10)$ & $0.1958(8)$ & $0.7397(4)$ & 1 & 4.34 \\
$\mathrm{O}(8)$ & $1 \mathrm{~d}$ & $0.4726(6)$ & $0.1684(4)$ & $0.3791(4)$ & 1 & $4.24(9)$ \\
$\mathrm{H}(8) \mathrm{A}$ & $1 \mathrm{~d}$ & $0.411(5)$ & $0.148(5)$ & $0.2797(15)$ & 1 & 5.05 \\
$\mathrm{H}(8) \mathrm{B}$ & $1 \mathrm{~d}$ & $0.564(4)$ & $0.256(3)$ & $0.394(4)$ & 1 & 5.05 \\
\hline
\end{tabular}


Table S3. Anisotropic displacement parameters $\left(\mathrm{ADP}, \AA^{2}\right)$ of $\mathrm{CoFeF}_{5}\left(\mathrm{H}_{2} \mathrm{O}\right)_{7}$ in triclinic system.

\begin{tabular}{|l|l|c|c|c|c|c|}
\hline Atom & \multicolumn{1}{|c|}{$\mathbf{U}_{11}$} & $\mathbf{U}_{\mathbf{2 2}}$ & $\mathbf{U}_{\mathbf{3 3}}$ & $\mathbf{U}_{\mathbf{2 3}}$ & $\mathbf{U}_{\mathbf{1 3}}$ & $\mathbf{U}_{\mathbf{1 2}}$ \\
\hline $\mathrm{Co}(1)$ & $0.0142(3)$ & $0.0176(4)$ & $0.0176(4)$ & $0.0045(3)$ & $0.0018(3)$ & $0.0010(3)$ \\
$\mathrm{Co}(2)$ & $0.0191(4)$ & $0.0170(4)$ & $0.0170(4)$ & $0.0037(3)$ & $0.0000(3)$ & $-0.0011(3)$ \\
$\mathrm{Fe}(1)$ & $0.0151(4)$ & $0.0174(4)$ & $0.0174(4)$ & $0.0050(3)$ & $0.0004(3)$ & $-0.0012(3)$ \\
$\mathrm{Fe}(2)$ & $0.0133(3)$ & $0.0212(4)$ & $0.0212(4)$ & $0.0035(3)$ & $-0.0004(3)$ & $-0.0003(3)$ \\
$\mathrm{F}(1)$ & $0.0443(17)$ & $0.0394(16)$ & $0.0394(16)$ & $0.0011(12)$ & $0.0174(13)$ & $-0.0029(13)$ \\
$\mathrm{O}(1)$ & $0.0443(17)$ & $0.0394(16)$ & $0.0394(16)$ & $0.0011(12)$ & $0.0174(13)$ & $-0.0029(13)$ \\
$\mathrm{F}(3)$ & $0.0299(13)$ & $0.0285(13)$ & $0.0285(13)$ & $0.0165(11)$ & $0.0059(11)$ & $0.0052(10)$ \\
$\mathrm{F}(4)$ & $0.0240(12)$ & $0.0442(15)$ & $0.0442(15)$ & $0.0141(12)$ & $-0.0078(10)$ & $-0.0161(11)$ \\
$\mathrm{F}(2)$ & $0.0365(16)$ & $0.0255(15)$ & $0.0255(15)$ & $0.0075(14)$ & $-0.0030(14)$ & $0.0073(12)$ \\
$\mathrm{O}(2)$ & $0.0365(16)$ & $0.0255(15)$ & $0.0255(15)$ & $0.0075(14)$ & $-0.0030(14)$ & $0.0073(12)$ \\
$\mathrm{F}(5)$ & $0.0188(11)$ & $0.0331(13)$ & $0.0331(13)$ & $0.0166(11)$ & $-0.0062(10)$ & $-0.0043(10)$ \\
$\mathrm{F}(6)$ & $0.0276(13)$ & $0.084(2)$ & $0.084(2)$ & $0.0247(14)$ & $0.0070(11)$ & $0.0131(14)$ \\
$\mathrm{O}(3)$ & $0.0161(13)$ & $0.0426(18)$ & $0.0426(18)$ & $0.0226(15)$ & $-0.0048(12)$ & $-0.0048(12)$ \\
$\mathrm{O}(4)$ & $0.0260(15)$ & $0.0253(16)$ & $0.0253(16)$ & $0.0192(15)$ & $0.0143(14)$ & $0.0068(12)$ \\
$\mathrm{O}(5)$ & $0.0214(14)$ & $0.0474(18)$ & $0.0474(18)$ & $0.0147(13)$ & $0.0047(11)$ & $0.0082(13)$ \\
$\mathrm{O}(6)$ & $0.0302(16)$ & $0.0396(18)$ & $0.0396(18)$ & $0.0100(13)$ & $-0.0059(12)$ & $-0.0155(13)$ \\
$\mathrm{O}(7)$ & $0.0364(18)$ & $0.048(2)$ & $0.048(2)$ & $-0.0150(16)$ & $0.0104(15)$ & $-0.0064(15)$ \\
$\mathrm{O}(8)$ & $0.064(2)$ & $0.046(2)$ & $0.046(2)$ & $0.0308(17)$ & $-0.0302(18)$ & $-0.0334(18)$ \\
& & & & & & \\
\hline
\end{tabular}

Table S4. Selected inter-atomic distances $(\AA)$ and bond valence calculations of $\mathrm{CoFeF}_{5}\left(\mathrm{H}_{2} \mathrm{O}\right)_{7}$ in triclinic system.

\begin{tabular}{|c|l|l|}
\hline $\mathrm{Fe}(1)-\mathrm{F}(4) \times 2$ & $1.905(2)$ & \\
$\mathrm{Fe}(1)-\mathrm{F}(3) \times 2$ & $1.929(2)$ & $\Sigma \mathrm{Fe}(1)=3.05$ \\
$\mathrm{Fe}(1)-\mathrm{O}(1) / \mathrm{F}(1) \times 2$ & $1.971(3)$ & \\
$\mathrm{Fe}(2)-\mathrm{F}(6) \times 2$ & $1.902(2)$ & \\
$\mathrm{Fe}(2)-\mathrm{F}(5) \times 2$ & $1.903(2)$ & $\Sigma \mathrm{Fe}(2)=2.99$ \\
$\mathrm{Fe}(2)-\mathrm{O}(2) / \mathrm{F}(2) \times 2$ & $2.028(3)$ & \\
$\mathrm{Co}(1)-\mathrm{O}(3) \times 2$ & $2.048(3)$ & \\
$\mathrm{Co}(1)-\mathrm{O}(4) \times 2$ & $2.076(3)$ & $\Sigma \mathrm{Co}(1)=2.15$ \\
$\mathrm{Co}(1)-\mathrm{O}(5) \times 2$ & $2.090(3)$ & \\
$\mathrm{Co}(2)-\mathrm{O}(8) \times 2$ & $2.055(3)$ & \\
$\mathrm{Co}(2)-\mathrm{O}(6) \times 2$ & $2.085(3)$ & $\Sigma \mathrm{Co}(2)=2.11$ \\
$\mathrm{Co}(2)-\mathrm{O}(7) \times 2$ & $2.096(3)$ & \\
\hline
\end{tabular}


Table S5. Atomic coordinates and equivalent isotropic displacement parameters of $\mathrm{CoFeF}_{5}\left(\mathrm{H}_{2} \mathrm{O}\right)_{7}$ in monoclinic system.

\begin{tabular}{|c|c|c|c|c|c|c|}
\hline Atom & site & $\mathbf{x}$ & $\mathbf{y}$ & $\mathbf{z}$ & $\boldsymbol{\tau}$ & $\mathbf{B}_{\text {eq }}\left(\AA^{\mathbf{2}}\right)$ \\
\hline $\mathrm{Co}(1)$ & $2 \mathrm{~d}$ & 0 & $1 / 2$ & $1 / 2$ & 1 & $1.40(2)$ \\
$\mathrm{Co}(2)$ & $2 \mathrm{c}$ & 0 & 0 & $1 / 2$ & 1 & $1.49(2)$ \\
$\mathrm{Fe}(1)$ & $4 \mathrm{e}$ & $1 / 4$ & $1 / 4$ & 0 & 1 & $1.39(2)$ \\
$\mathrm{O}(1)$ & $8 \mathrm{j}$ & $0.1178(3)$ & $0.1672(3)$ & $0.0732(6)$ & 0.5 & $5.83(2)$ \\
$\mathrm{F}(1)$ & $8 \mathrm{j}$ & $0.1178(3)$ & $0.1672(3)$ & $0.0732(6)$ & 0.5 & $5.83(2)$ \\
$\mathrm{F}(2)$ & $8 \mathrm{j}$ & $0.3357(3)$ & $0.24344(19)$ & $0.2788(4)$ & 1 & $3.23(6)$ \\
$\mathrm{F}(3)$ & $8 \mathrm{j}$ & $0.1702(4)$ & $0.3629(2)$ & $0.0683(4)$ & 1 & $5.31(13)$ \\
$\mathrm{O}(2)$ & $8 \mathrm{j}$ & $0.1280(3)$ & $0.3969(2)$ & $0.4500(5)$ & 1 & $2.45(5)$ \\
$\mathrm{H}(2) \mathrm{A}$ & $8 \mathrm{j}$ & $0.139(4)$ & $0.3738(18)$ & $0.327(2)$ & 1 & 2.92 \\
$\mathrm{H}(2) \mathrm{B}$ & $8 \mathrm{j}$ & $0.143(4)$ & $0.3475(12)$ & $0.539(3)$ & 1 & 2.92 \\
$\mathrm{O}(3)$ & $4 \mathrm{i}$ & $-0.0733(4)$ & 0.500000 & $0.1897(6)$ & 1 & $2.60(9)$ \\
$\mathrm{H}(3) \mathrm{A}$ & $8 \mathrm{j}$ & $-0.094(4)$ & $0.55103(4)$ & $0.1074(18)$ & 1 & 3.08 \\
$\mathrm{O}(4)$ & $4 \mathrm{i}$ & $-0.1436(4)$ & 0.000000 & $0.6737(7)$ & 1 & $3.40(10)$ \\
$\mathrm{H}(4) \mathrm{A}$ & $8 \mathrm{j}$ & $-0.153(4)$ & $-0.05103(4)$ & $0.753(3)$ & 1 & 4.11 \\
$\mathrm{O}(5)$ & $4 \mathrm{~h}$ & 0.000000 & $0.1449(3)$ & 0.500000 & 1 & $4.61(2)$ \\
$\mathrm{H}(5) \mathrm{A}$ & $8 \mathrm{j}$ & $0.0618(11)$ & $0.1839(4)$ & $0.557(5)$ & 1 & 5.53 \\
$\mathrm{O}(6)$ & $4 \mathrm{i}$ & $-0.1300(4)$ & 0.000000 & $0.2255(7)$ & 1 & $2.50(8)$ \\
$\mathrm{H}(6) \mathrm{A}$ & $8 \mathrm{j}$ & $-0.149(4)$ & $-0.05103(4)$ & $0.1427(16)$ & 1 & 3.00 \\
\hline
\end{tabular}

Table S6. Anisotropic displacement parameters (ADP, $\left.\AA^{2}\right)$ of $\mathrm{CoFeF}_{5}\left(\mathrm{H}_{2} \mathrm{O}\right)_{7}$ in monoclinic system.

\begin{tabular}{|c|l|c|c|c|c|c|}
\hline Atom & \multicolumn{1}{|c|}{$\mathbf{U}_{\mathbf{1 1}}$} & $\mathbf{U}_{\mathbf{2 2}}$ & $\mathbf{U}_{\mathbf{3 3}}$ & $\mathbf{U}_{\mathbf{2 3}}$ & $\mathbf{U}_{\mathbf{1 3}}$ & $\mathbf{U}_{\mathbf{1 2}}$ \\
\hline $\mathrm{Co}(1)$ & $0.0184(5)$ & $0.0211(5)$ & $0.0132(5)$ & 0 & $0.0024(4)$ & 0 \\
$\mathrm{Co}(2)$ & $0.0177(5)$ & $0.0185(5)$ & $0.0189(5)$ & 0 & $-0.0007(4)$ & 0 \\
$\mathrm{Fe}(1)$ & $0.0187(4)$ & $0.0192(4)$ & $0.0139(4)$ & $0.0002(3)$ & $0.0003(3)$ & $0.0007(3)$ \\
$\mathrm{O}(1)$ & $0.0402(18)$ & $0.105(3)$ & $0.069(3)$ & $0.053(2)$ & $-0.0115(17)$ & $-0.035(2)$ \\
$\mathrm{F}(1)$ & $0.0402(18)$ & $0.105(3)$ & $0.069(3)$ & $0.053(2)$ & $-0.0115(17)$ & $-0.035(2)$ \\
$\mathrm{F}(2)$ & $0.0556(17)$ & $0.0363(15)$ & $0.0223(13)$ & $0.0036(12)$ & $-0.0155(12)$ & $-0.0087(13)$ \\
$\mathrm{F}(3)$ & $0.114(3)$ & $0.062(2)$ & $0.0292(16)$ & $0.0079(15)$ & $0.0219(17)$ & $0.063(2)$ \\
$\mathrm{O}(2)$ & $0.0419(17)$ & $0.0306(16)$ & $0.0234(15)$ & $0.0039(13)$ & $0.0136(13)$ & $0.0147(14)$ \\
$\mathrm{O}(3)$ & $0.048(3)$ & $0.028(2)$ & $0.019(2)$ & 0 & $-0.0031(19)$ & 0 \\
$\mathrm{O}(4)$ & $0.028(2)$ & $0.071(4)$ & $0.029(3)$ & 0 & $0.005(2)$ & 0 \\
$\mathrm{O}(5)$ & $0.063(3)$ & $0.020(2)$ & $0.073(4)$ & 0 & $-0.040(3)$ & 0 \\
$\mathrm{O}(6)$ & $0.036(2)$ & $0.028(2)$ & $0.025(2)$ & 0 & $-0.0113(18)$ & 0 \\
& & & & & & \\
& & & & & & \\
& & & & & & \\
\hline
\end{tabular}


Table S7. Selected inter-atomic distances $(\AA)$ and bond valence calculations in $\operatorname{CoFeF}_{5}\left(\mathrm{H}_{2} \mathrm{O}\right)_{7}$ in monoclinic system.

\begin{tabular}{|c|l|l|}
\hline $\mathrm{Co}(1)-\mathrm{O}(3) \mathrm{x} 2$ & $2.050(4)$ & \\
$\mathrm{Co}(1)-\mathrm{O}(2) \mathrm{x} 4$ & $2.084(3)$ & $\Sigma \mathrm{Co}(1)=2.15$ \\
$\mathrm{Co}(2)-\mathrm{O}(5) \mathrm{x} 2$ & $2.030(5)$ & \\
$\mathrm{Co}(2)-\mathrm{O}(6) \mathrm{x} 2$ & $2.087(4)$ & $\Sigma \mathrm{Co}(2)=2.14$ \\
$\mathrm{Co}(2)-\mathrm{O}(4) \mathrm{x} 2$ & $2.109(5)$ & \\
$\mathrm{Co}(1)-\mathrm{F}(3) \mathrm{x} 2$ & $1.902(3)$ & $\Sigma \mathrm{Fe}(1)=3.10$ \\
$\mathrm{Fe}(1)-\mathrm{F}(2) \times 2$ & $1.902(2)$ & \\
$\mathrm{Fe}(1)-\mathrm{O}(1) / \mathrm{F}(1) \times 2$ & $1.986(3)$ & \\
\hline
\end{tabular}

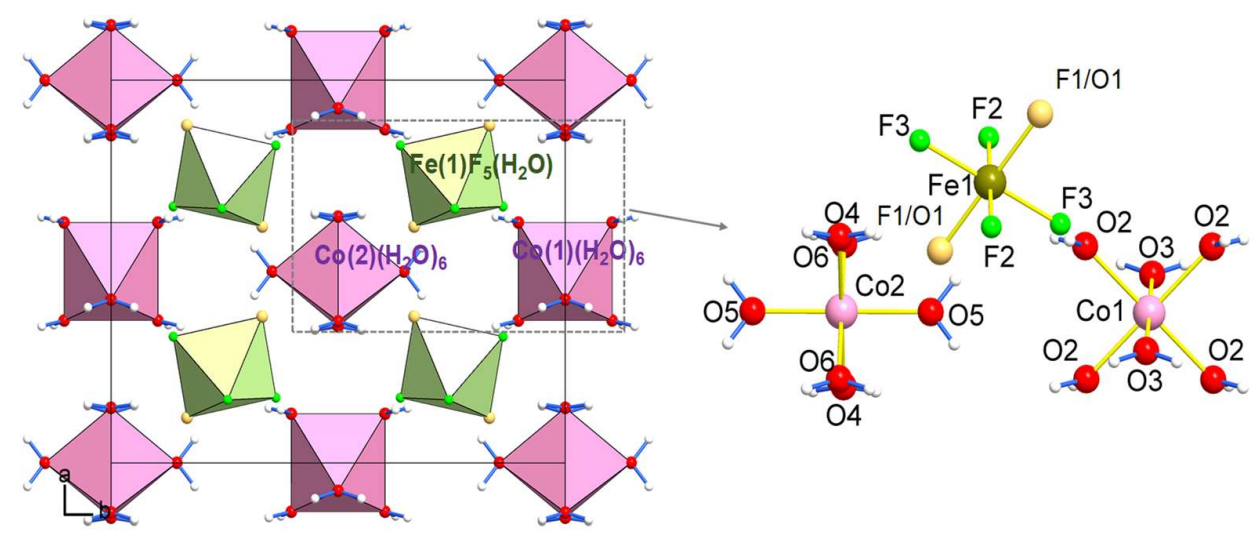

Figure S2. [001] projection of the structure of $\mathrm{CoFeF}_{5}\left(\mathrm{H}_{2} \mathrm{O}\right)_{7}$ (left) and view of the isolated $\mathrm{Co}\left(\mathrm{H}_{2} \mathrm{O}\right)_{6}$ and $\mathrm{FeF}_{5}\left(\mathrm{H}_{2} \mathrm{O}\right)$ entities (right).
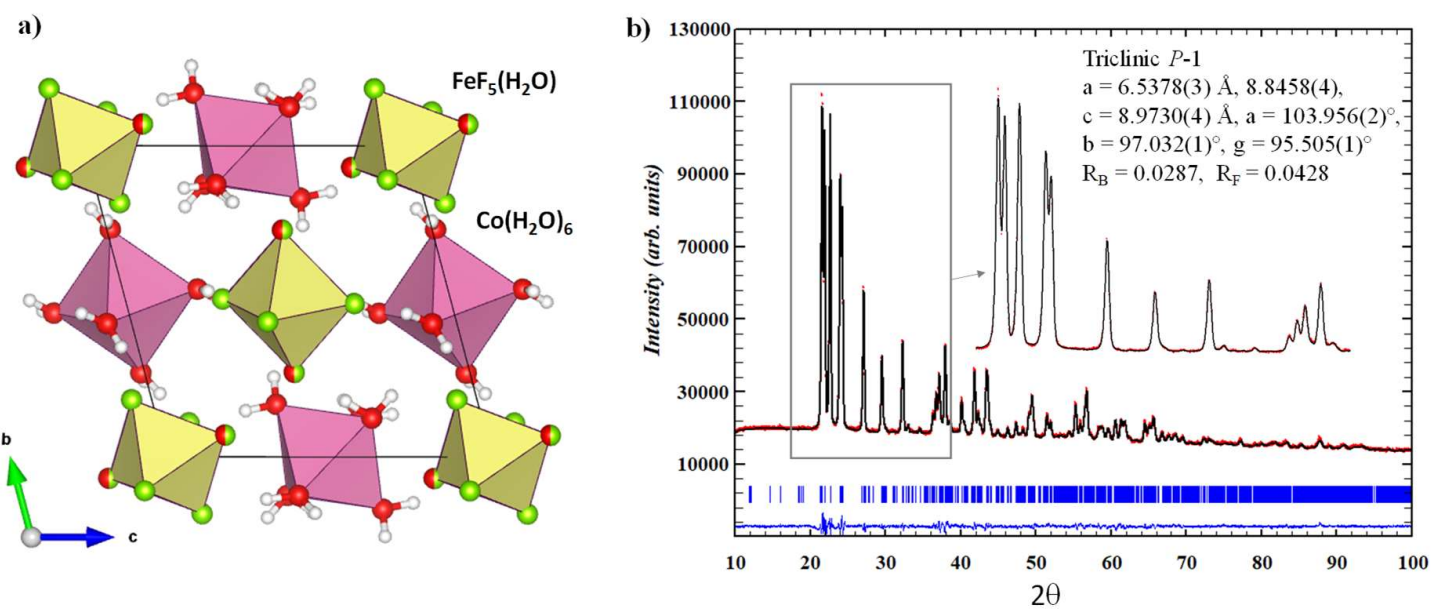

Figure S3. a) [100] projection of the structure of $\mathrm{CoFeF}_{5}\left(\mathrm{H}_{2} \mathrm{O}\right)_{7}$. b) Rietveld refinement of $\mathrm{CoFeF}_{5}\left(\mathrm{H}_{2} \mathrm{O}\right)_{7}$ PXRD pattern (experimental in black, calculated in red, difference between experimental and calculated patterns in blue, Bragg positions in blue sticks). The inset shows a zoom. 
Table S8. Selected H-bond distances $\mathrm{O}-\mathrm{H} \cdots \mathrm{F} / \mathrm{O}$ and angles in $\mathrm{CoFeF}_{5}\left(\mathrm{H}_{2} \mathrm{O}\right)_{7}$ (triclinic system).

\begin{tabular}{|c|c|c|c|c|}
\hline $\mathbf{O}-\mathbf{H}$ & $\mathbf{d}(\mathbf{H} \cdots \mathbf{A})(\mathbf{\AA})$ & $\left\langle\mathbf{D H A}>\mathbf{(}^{\circ}\right)$ & $\mathbf{d}(\mathbf{O} \cdots \mathbf{A})(\mathbf{\AA})$ & $\mathbf{A}$ \\
\hline $\mathrm{O}(3)-\mathrm{H}(3) \mathrm{A}$ & 1.813 & 162.99 & 2.686 & $\mathrm{~F}(3)$ \\
$\mathrm{O}(3)-\mathrm{H}(3) \mathrm{B}$ & 1.737 & 170.71 & 2.629 & $\mathrm{~F}(6)$ \\
$\mathrm{O}(4)-\mathrm{H}(4) \mathrm{A}$ & 1.817 & 161.78 & 2.686 & $\mathrm{~F}(3)$ \\
$\mathrm{O}(4)-\mathrm{H}(4) \mathrm{B}$ & 1.765 & 161.04 & 2.633 & $\mathrm{~F}(4)$ \\
$\mathrm{O}(5)-\mathrm{H}(5) \mathrm{A}$ & 1.762 & 173.45 & 2.658 & $\mathrm{~F}(5)$ \\
$\mathrm{O}(5)-\mathrm{H}(5) \mathrm{B}$ & 1.789 & 172.51 & 2.684 & $\mathrm{~F}(6)$ \\
$\mathrm{O}(6)-\mathrm{H}(6) \mathrm{A}$ & 1.967 & 166.14 & 2.849 & $\mathrm{~F}(2)$ \\
$\mathrm{O}(6)-\mathrm{H}(6) \mathrm{B}$ & 1.842 & 172.84 & 2.738 & $\mathrm{~F}(3)$ \\
$\mathrm{O}(7)-\mathrm{H}(7) \mathrm{A}$ & 2.181 & 156.20 & 3.026 & $\mathrm{~F}(2)$ \\
$\mathrm{O}(7)-\mathrm{H}(7) \mathrm{A}$ & 2.417 & 113.81 & 2.900 & $\mathrm{O}(8)$ \\
$\mathrm{O}(7)-\mathrm{H}(7) \mathrm{B}$ & 2.216 & 148.61 & 3.020 & $\mathrm{O}(4)$ \\
$\mathrm{O}(7)-\mathrm{H}(7) \mathrm{B}$ & 2.380 & 132.63 & 3.062 & $\mathrm{O}(5)$ \\
$\mathrm{O}(8)-\mathrm{H}(8) \mathrm{A}$ & 1.730 & 173.65 & 2.627 & $\mathrm{~F}(4)$ \\
$\mathrm{O}(8)-\mathrm{H}(8) \mathrm{B}$ & 1.736 & 172.97 & 2.631 & $\mathrm{~F}(5)$ \\
\hline
\end{tabular}

Table S9. Selected H-bond distances $\mathrm{O}-\mathrm{H} \cdots \mathrm{F} / \mathrm{O}$ and angles in $\mathrm{CoFeF}_{5}\left(\mathrm{H}_{2} \mathrm{O}\right)_{7}($ monoclinic system).

\begin{tabular}{|c|c|c|c|c|}
\hline $\mathbf{O}-\mathbf{H}$ & $\mathbf{d}(\mathbf{H} \cdots \mathbf{A})(\mathbf{\AA})$ & $\left\langle\mathbf{D H A}>\mathbf{(}^{\circ}\right)$ & $\mathbf{d}(\mathbf{O} \cdots \mathbf{A})(\mathbf{\AA})$ & $\mathbf{A}$ \\
\hline $\mathrm{O}(2)-\mathrm{H}(2) \mathrm{A}$ & 1.797 & 163.57 & 2.672 & $\mathrm{~F}(3)$ \\
$\mathrm{O}(2)-\mathrm{H}(2) \mathrm{B}$ & 1.736 & 175.43 & 2.634 & $\mathrm{~F}(2)$ \\
$\mathrm{O}(3)-\mathrm{H}(3) \mathrm{A}$ & 1.771 & 165.86 & 2.653 & $\mathrm{~F}(3)$ \\
$\mathrm{O}(4)-\mathrm{H}(4) \mathrm{A}$ & 1.986 & 162.39 & 2.857 & $\mathrm{~F}(1) / \mathrm{O}(1)$ \\
$\mathrm{O}(5)-\mathrm{H}(5) \mathrm{A}$ & 1.739 & 165.98 & 2.621 & $\mathrm{~F}(2)$ \\
$\mathrm{O}(6)-\mathrm{H}(6) \mathrm{A}$ & 2.299 & 130.19 & 2.960 & $\mathrm{~F}(3)$ \\
$\mathrm{O}(6)-\mathrm{H}(6) \mathrm{A}$ & 2.226 & 156.69 & 3.073 & $\mathrm{~F}(1) / \mathrm{O}(1)$ \\
\hline
\end{tabular}

Table S10. Atomic coordinates and equivalent ADP of $\mathrm{CoFeF}_{5}\left(\mathrm{H}_{2} \mathrm{O}\right)_{7}$ in triclinic system from powder data.

\begin{tabular}{|c|c|c|c|c|c|}
\hline Atom & Site & $\mathbf{x}$ & $\mathbf{y}$ & $\mathbf{z}$ & $B_{\mathrm{eq}}\left(\AA^{2}\right)$ \\
\hline $\mathrm{Co}(1)$ & $2 \mathrm{~d}$ & & & & $3.26(5)$ \\
\hline $\mathrm{Co}(2)$ & $2 d$ & $1 / 2$ & $1 / 2$ & 0 & $3.26(5)$ \\
\hline $\mathrm{Fe}(1)$ & $2 d$ & $1 / 2$ & 0 & $1 / 2$ & $3.26(5)$ \\
\hline $\mathrm{Fe}(2)$ & $2 d$ & 0 & 0 & 0 & $3.26(5)$ \\
\hline $\mathrm{F}(1)$ & $1 \mathrm{~d}$ & $\begin{array}{c}0 \\
0.0976(11)\end{array}$ & $\begin{array}{c}1 / 2 \\
024(0)\end{array}$ & $1 / 2$ & $4.18(7)$ \\
\hline $\mathrm{O}(1)$ & $1 d$ & $0.0976(11)$ & $0.9242(9)$ & $0.7921(10)$ & $4.18(7)$ \\
\hline $\mathrm{F}(3)$ & $1 d$ & $\begin{array}{l}0.09 / 0(11) \\
0.9259(13)\end{array}$ & $\begin{array}{l}0.9242(9) \\
0.1837(9)\end{array}$ & $\begin{array}{c}0.7921(10) \\
0.9403(9)\end{array}$ & $4.18(7)$ \\
\hline $\mathrm{F}(4)$ & $1 d$ & $0.7257(16)$ & $0.8973(12)$ & $0.9091(10)$ & $4.18(7)$ \\
\hline $\mathrm{F}(2)$ & $1 d$ & $0.9533(17)$ & $0.7241(14)$ & $0.5391(11)$ & $4.18(7)$ \\
\hline $\mathrm{O}(2)$ & $1 d$ & $0.9533(17)$ & $0.7241(14)$ & $0.5391(11)$ & $4.18(7)$ \\
\hline $\mathrm{F}(5)$ & $1 d$ & $0.7107(17)$ & $0.4311(12)$ & $0.4116(10)$ & $4.18(7)$ \\
\hline $\mathrm{F}(6)$ & $1 d$ & $0.0633(13)$ & $0.5110(0)$ & $0.2992(9)$ & $4.18(7)$ \\
\hline $\mathrm{O}(3)$ & $1 d$ & $0.8210(14)$ & $0.5713(11)$ & $0.0766(11)$ & $4.18(7)$ \\
\hline $\mathrm{O}(4)$ & $1 d$ & $0.4525(18)$ & $0.7374(13)$ & $0.0107(12)$ & $4.18(7)$ \\
\hline $\mathrm{O}(5)$ & $1 d$ & $0.5557(15)$ & $0.4610(10)$ & $0.7724(8)$ & $4.18(7)$ \\
\hline $\mathrm{O}(6)$ & $1 d$ & $\begin{array}{c}0.2268(8) \\
0.3336(11)\end{array}$ & $-0.1292(11)$ & $0.3720(10)$ & $4.18(7)$ \\
\hline $\mathrm{O}(7)$ & $1 d$ & $\begin{array}{l}0.3336(11) \\
0.4638(15)\end{array}$ & $\begin{array}{c}0.1267(8) \\
0.1651(10)\end{array}$ & $\begin{array}{l}0.6559(9) \\
0.3779(9)\end{array}$ & $4.18(7)$ \\
\hline $\mathrm{O}(8)$ & $1 d$ & & & & $4.18(7)$ \\
\hline
\end{tabular}


Table S11. ${ }^{57} \mathrm{Fe}$ Mössbauer spectrometry results for $\mathrm{CoFeF}_{5}\left(\mathrm{H}_{2} \mathrm{O}\right)_{7}$.

\begin{tabular}{|c|c|c|c|c|}
\hline Temperature & $\mathbf{F e}^{\mathbf{n}+}$ & $\begin{array}{c}\mathbf{d}(\mathbf{m m} / \mathbf{s}) \\
\mathbf{\pm 0 . 0 1}\end{array}$ & $\begin{array}{c}\mathbf{E}_{\mathbf{Q}}(\mathbf{m m} / \mathbf{s}) \\
\mathbf{\pm 0 . 0 2}\end{array}$ & $\begin{array}{c}\mathbf{\%} \\
\mathbf{\pm 2}\end{array}$ \\
\hline \multirow{3}{*}{$300 \mathrm{~K}$} & $\mathrm{Fe}^{3+}\left(\mathrm{FeF}_{6}\right)$ & 0.45 & 0.27 & 25 \\
& $\mathrm{Fe}^{3+}\left(\mathrm{FeF}_{5}\left(\mathrm{H}_{2} \mathrm{O}\right)\right)$ & 0.43 & 0.59 & 50 \\
& $\mathrm{Fe}^{3+}\left(\mathrm{FeF}_{4}\left(\mathrm{H}_{2} \mathrm{O}\right)_{2}\right)$ & 0.42 & 0.95 & 25 \\
\hline \multirow{3}{*}{$77 \mathrm{~K}$} & $\mathrm{Fe}^{3+}\left(\mathrm{FeF}_{6}\right)$ & 0.55 & 0.30 & 25 \\
& $\mathrm{Fe}^{3+}\left(\mathrm{FeF}_{5}\left(\mathrm{H}_{2} \mathrm{O}\right)\right)$ & 0.54 & 0.63 & 50 \\
& $\mathrm{Fe}^{3+}\left(\mathrm{FeF}_{4}\left(\mathrm{H}_{2} \mathrm{O}\right)_{2}\right)$ & 0.52 & 0.96 & 25 \\
\hline
\end{tabular}

a)

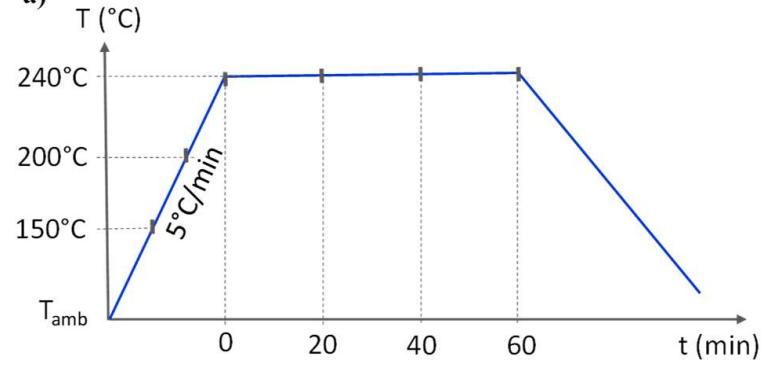

b)

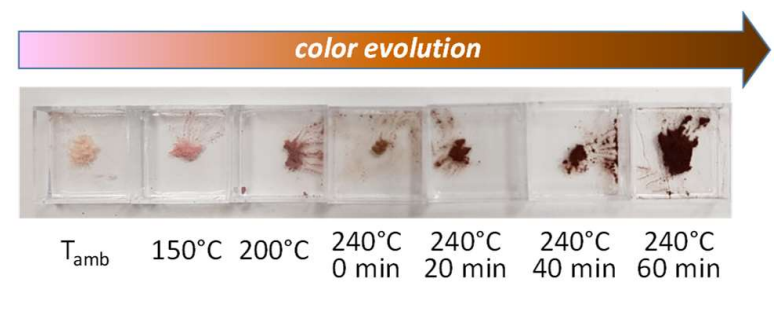

Figure S4: Calcination profile (a) and color evolution (b) as function as the thermal conditions (time, temperature) of $\mathrm{CoFeF}_{5}\left(\mathrm{H}_{2} \mathrm{O}\right)_{7}$ under ambient air.

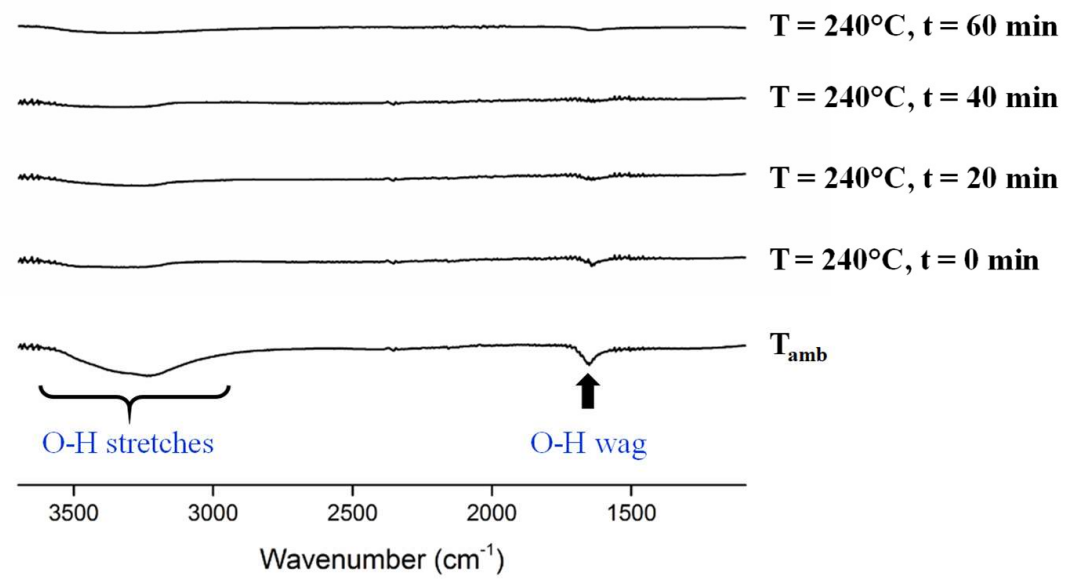

Figure S5: FT-IR of $\mathrm{CoFeF}_{5}\left(\mathrm{H}_{2} \mathrm{O}\right)_{7}$ during the thermal treatment. 
ToFeF ${ }_{5}\left(\mathrm{H}_{2} \mathrm{O}\right)_{7}$

T. $\mathrm{CoFeF}_{5}\left(\mathrm{H}_{2} \mathrm{O}\right)_{2}$

- $\mathrm{Co}_{0.5} \mathrm{Fe}_{0.5} \mathrm{O}_{0.5} \mathrm{~F}_{1.5}$ (isotype of FeOF)

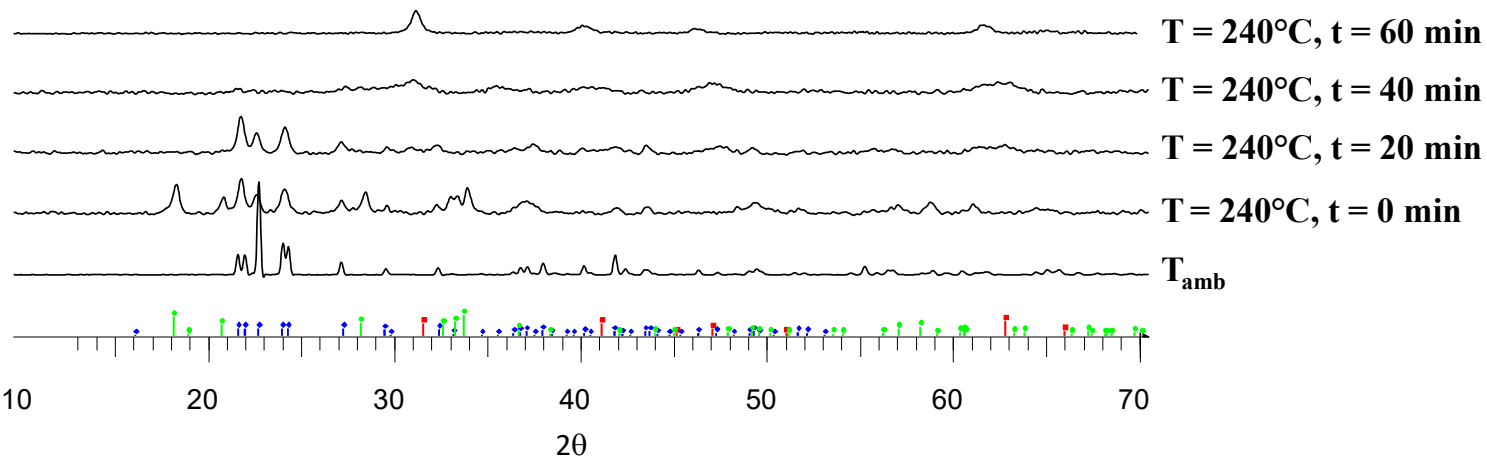

Figure S6: $\mathrm{XRD}$ pattern of $\mathrm{CoFeF}_{5}\left(\mathrm{H}_{2} \mathrm{O}\right)_{7}$ during the thermal treatment.

a)
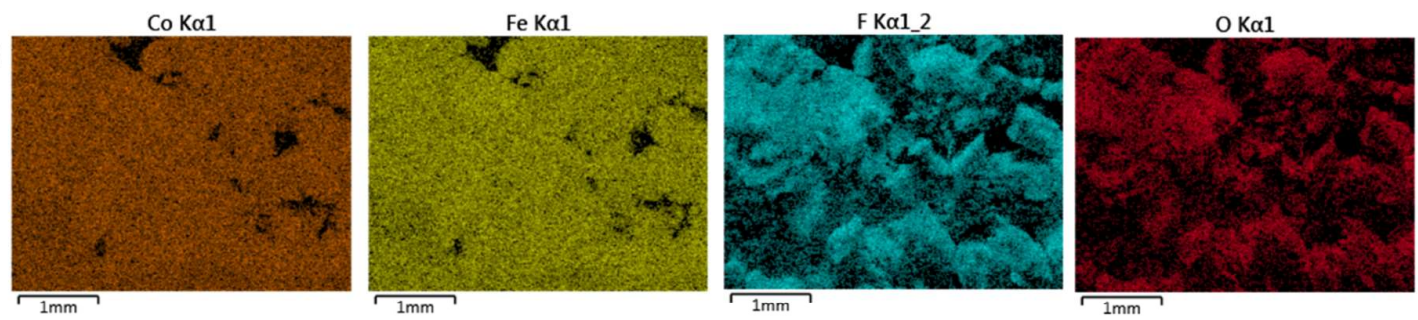

b)
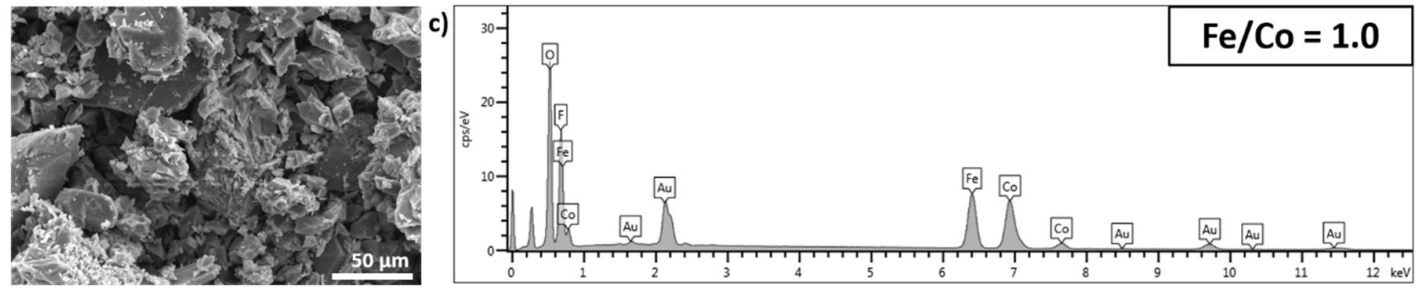

Figure S7: a) EDS mapping of $\mathrm{CoFeF}_{5}\left(\mathrm{H}_{2} \mathrm{O}\right)_{7}$ (triclinic system) b) Corresponding SEM image and c) EDS spectrum. 


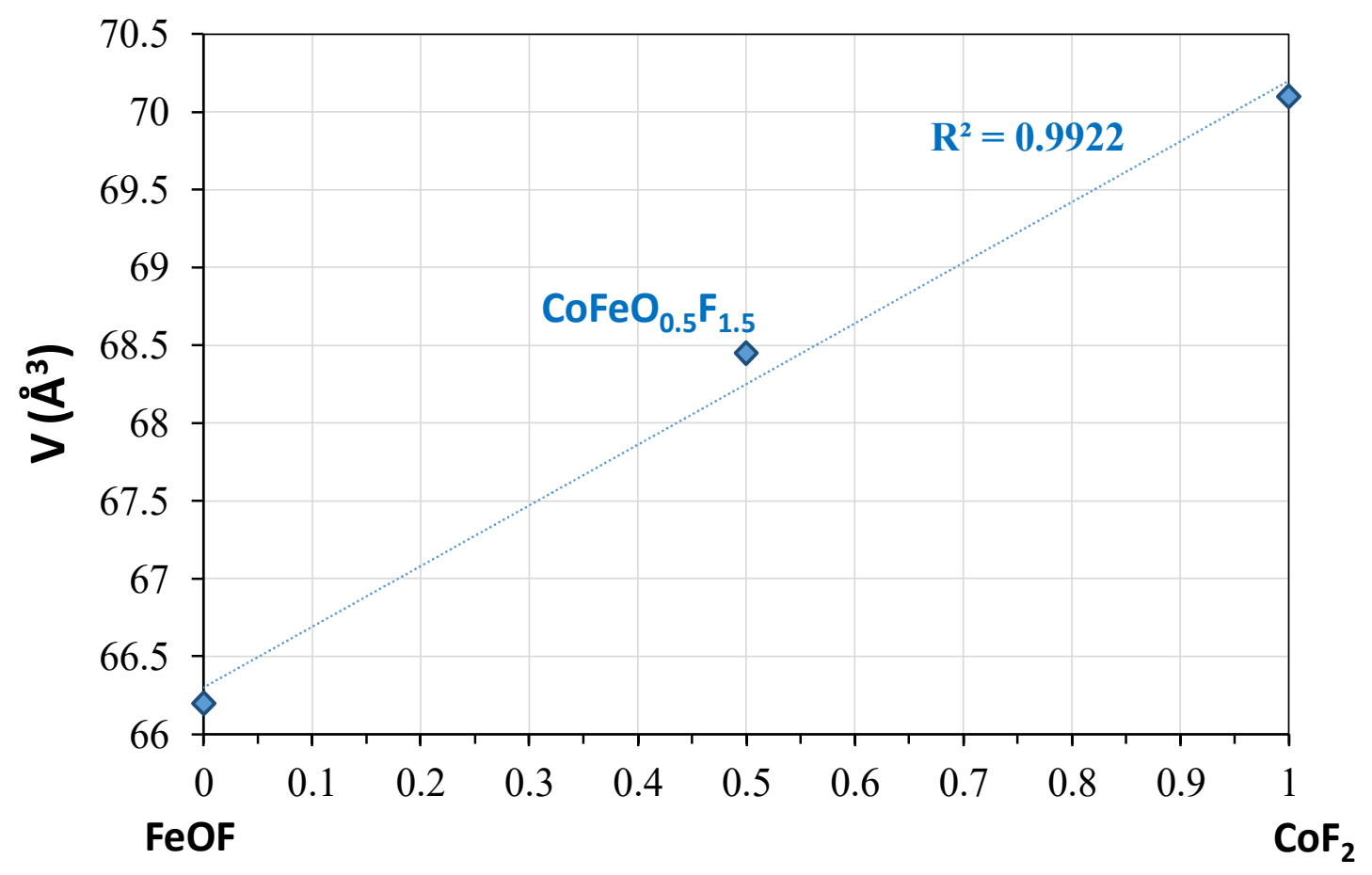

Figure S8: Vegard's Law of $\mathrm{xCoF}_{2} /(1-\mathrm{x}) \mathrm{FeOF}$
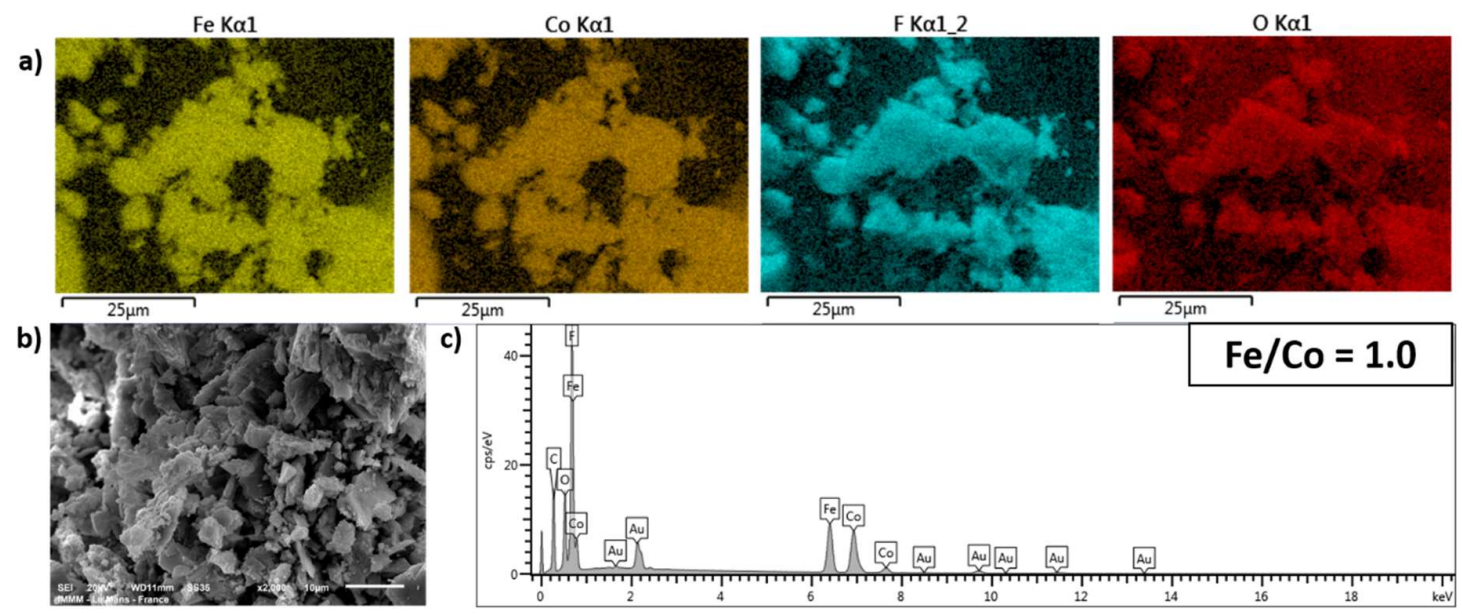

Figure S9: a) EDS mapping of $\mathrm{Co}_{0.5} \mathrm{Fe}_{0.5} \mathrm{O}_{0.5} \mathrm{~F}_{1.5}$ b) Corresponding SEM image and c) EDS spectrum. 

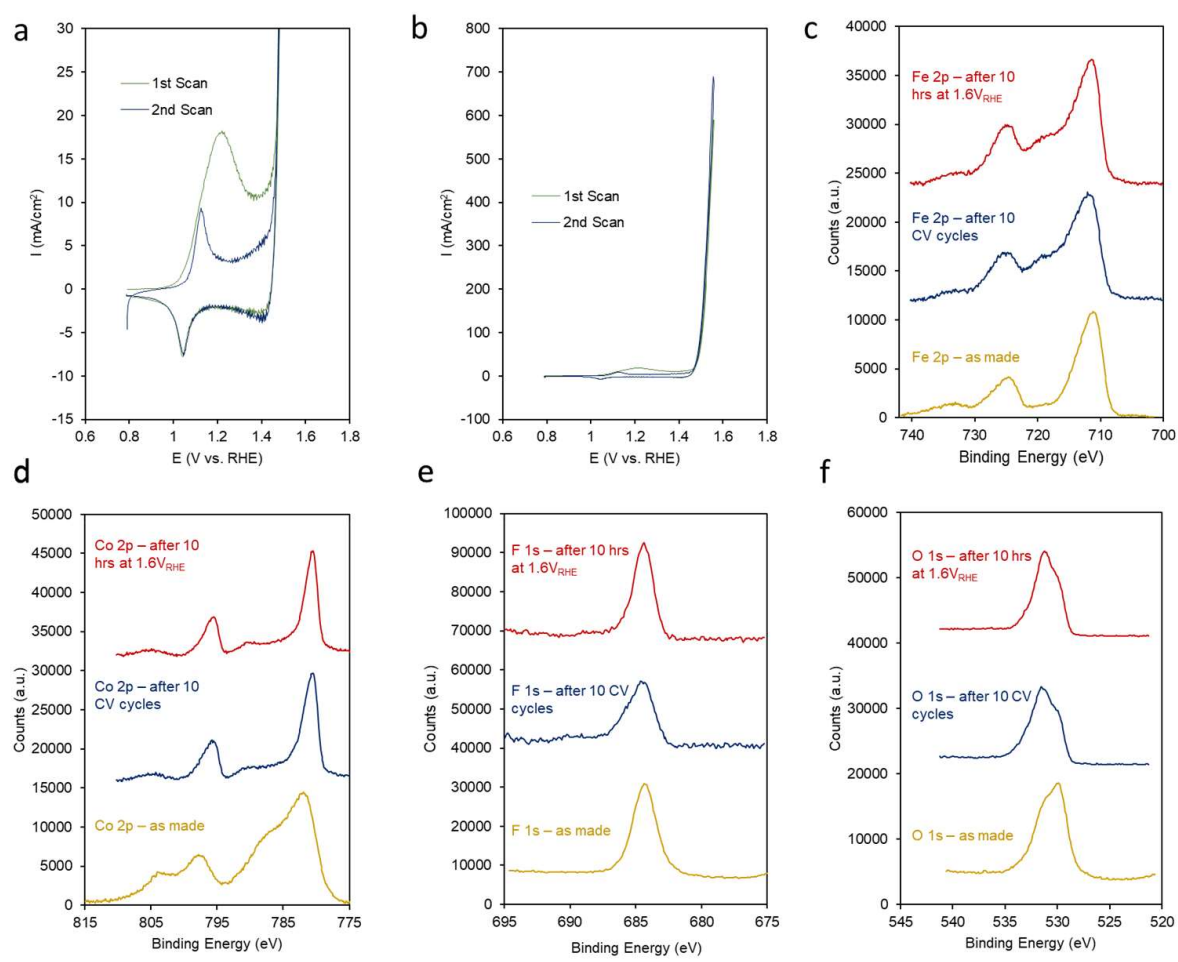

e

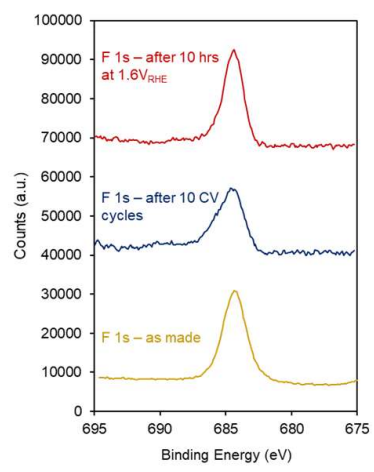

f

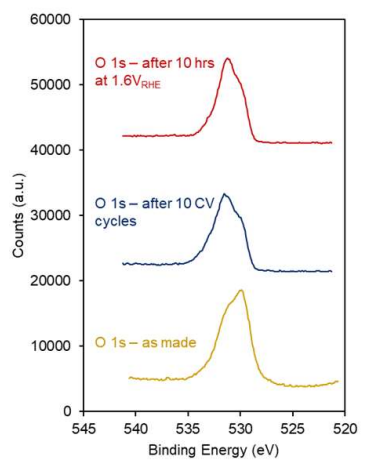

Figure S4: Differences between $1^{\text {st }}$ and $2^{\text {nd }} \mathrm{CVs}$ of $\mathrm{Co}_{0.5} \mathrm{Fe}_{0.5} \mathrm{O}_{0.5} \mathrm{~F}_{1.5}$ in $1 \mathrm{M} \mathrm{KOH}$ illustrate that a surface reconstruction process likely occurs $(\mathrm{a}, \mathrm{b})$. From the XPS data on the catalyst after $10 \mathrm{CV}$ cycles $\left(0.8\right.$ to $1.55 \mathrm{~V}_{\mathrm{RHE}}$ at $\left.20 \mathrm{mV} / \mathrm{s}\right)$ and after extended electrolysis $\left(10 \mathrm{hrs}\right.$ at $\left.1.6 \mathrm{~V}_{\mathrm{RHE}}\right)$, the restructuration stops after the first $\mathrm{CV}$ (c-f). The largest changes occur to the cobalt and oxygen spectra and indicate that the surface cobalt species becomes terminated with $\mathrm{O} / \mathrm{OH}$. 
a

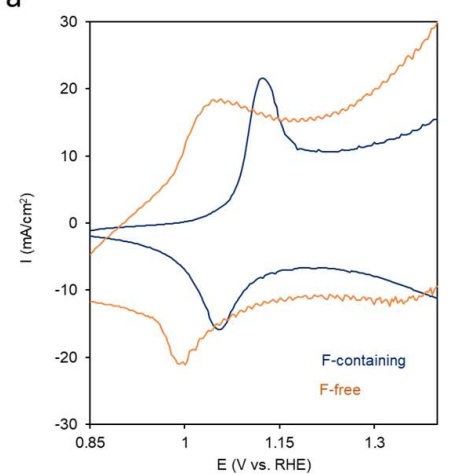

b

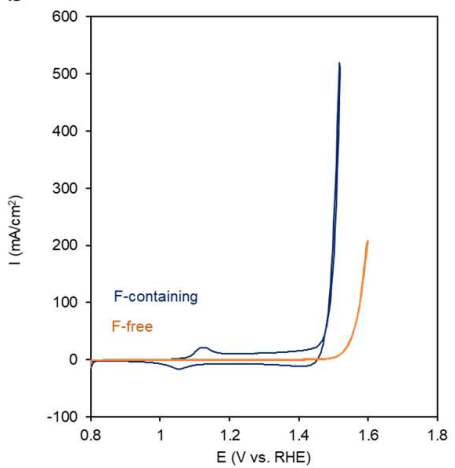

C

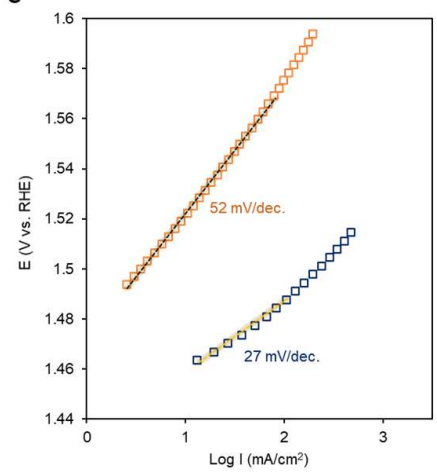

Figure S5: $\mathrm{Co}_{0.5} \mathrm{Fe}_{0.5} \mathrm{O}_{0.5} \mathrm{~F}_{1.5}$ was annealed at $500^{\circ} \mathrm{C}$ to remove the $\mathrm{F}$ component and generate $\mathrm{CoO}+$ $\mathrm{CoFe}_{2} \mathrm{O}_{4}$. This resulted in a negative shift of the Co redox wave (a), an overall decreased catalytic activity (b) and elevated Tafel slope (c).

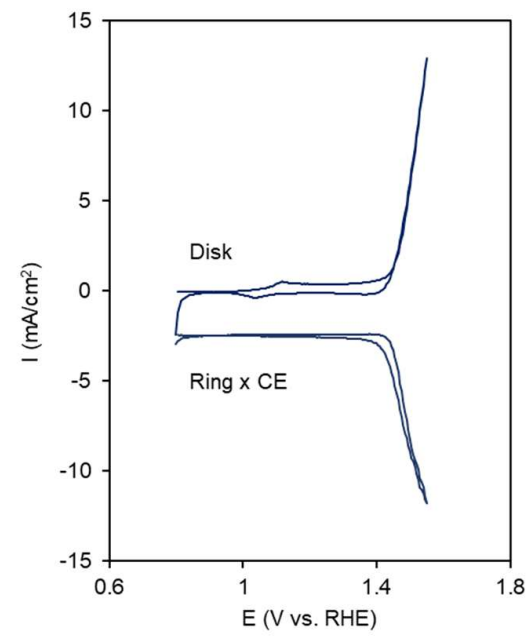

Figure S6: Rotating ring disk electrode measurements (1M KOH, no IR correction), confirming oxygen production as the source of the catalytic current. A glassy carbon electrode loaded with $\mathrm{Co}_{0.5} \mathrm{Fe}_{0.5} \mathrm{O}_{0.5} \mathrm{~F}_{1.5}\left(0.1 \mathrm{mg} / \mathrm{cm}^{2}\right)$ was used, and the Pt ring electrode poised $0.1 \mathrm{~V}$ vs. RHE. 


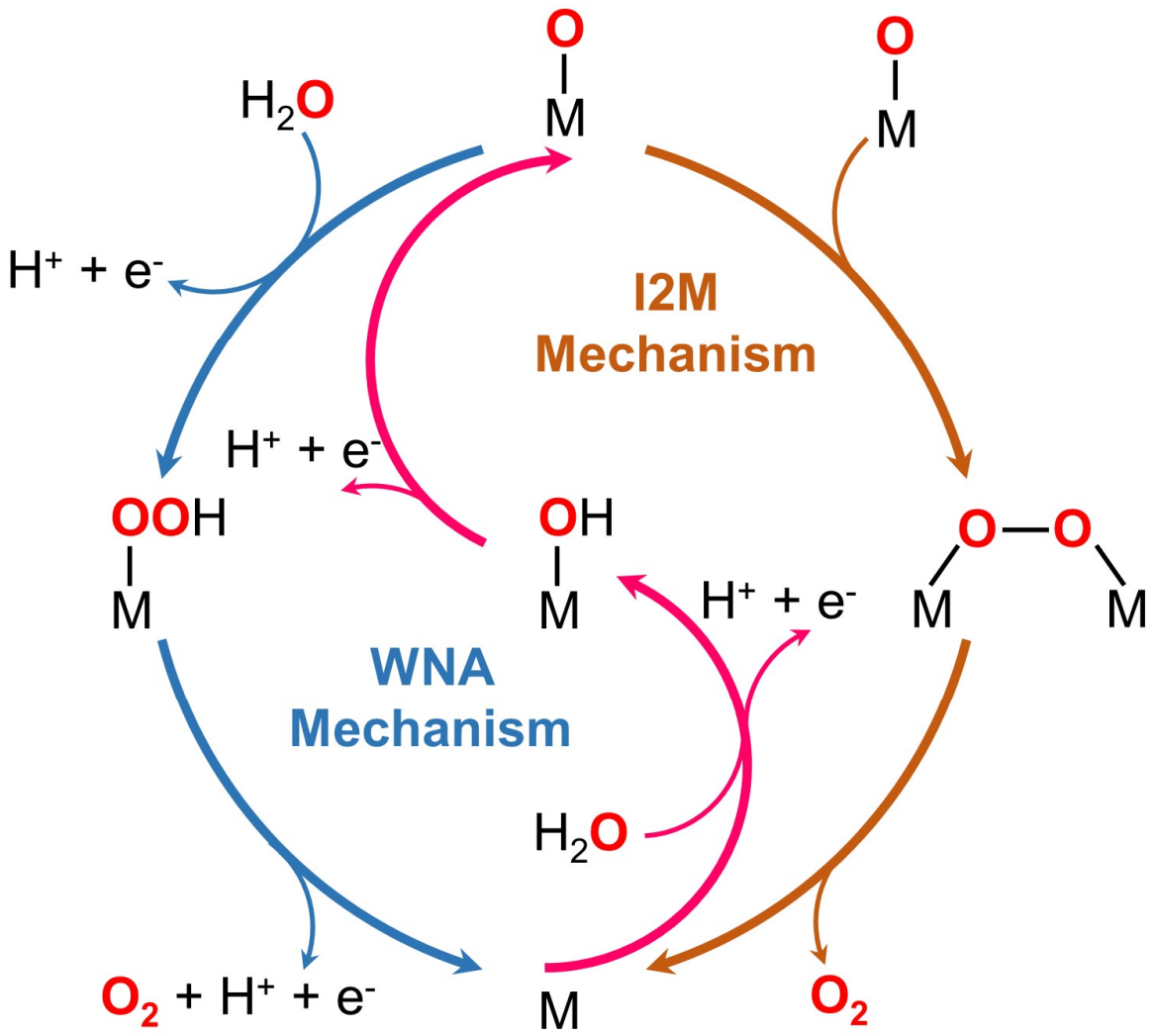

Figure S13: The two primary reaction pathways, i.e., water nucleophilic attack (WNA) and interaction of two metal-oxo units (I2M) mechanisms for the OER. 

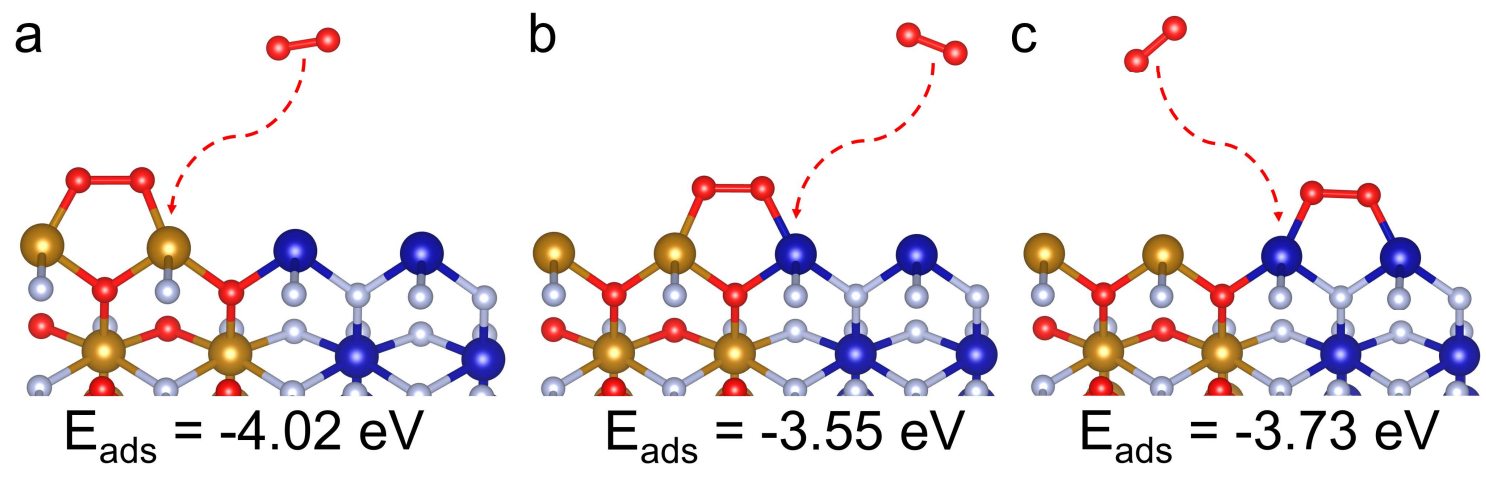

Figure S14: Adsorption energies of $\mathrm{O}_{2}$ at different possible active sites including two adjacent $\mathrm{Fe}$ atoms (a), two adjacent $\mathrm{Fe}$ and $\mathrm{Co}$ atoms (b), and two adjacent $\mathrm{Co}$ atoms (c).
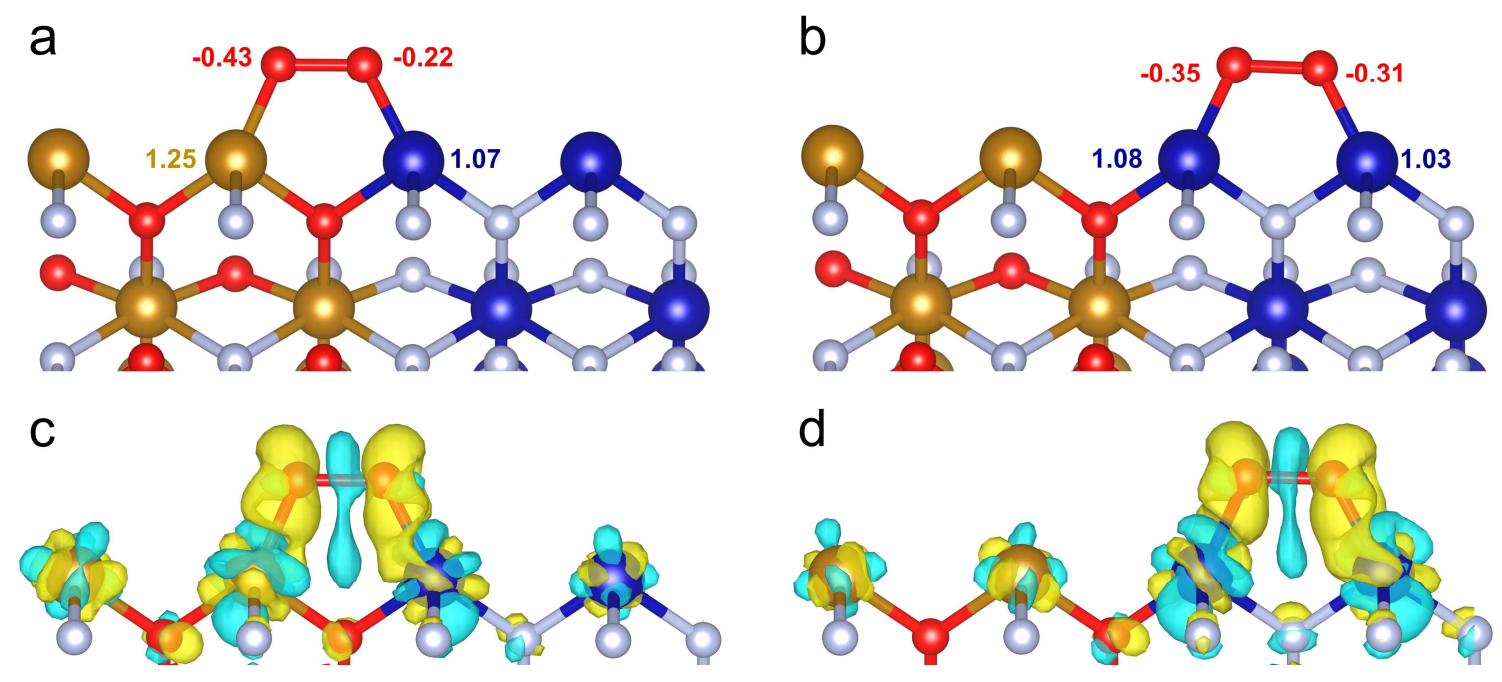

Figure S15: The Bader charge distribution and the corresponding charge density difference at the *O$\mathrm{O}^{*}$ coupling sites including two adjacent $\mathrm{Fe}$ and $\mathrm{Co}$ atoms $(\mathbf{a}, \mathbf{c})$ and two adjacent $\mathrm{Co}$ atoms $(\mathbf{b}, \mathbf{d})$. 


\section{References:}

1 Fawzy, S., Osman, A. I., Doran, J. \& Rooney, D. W. Strategies for mitigation of climate change: a review. Environ. Chem. Lett. 18, 2069-2094 (2020).

2 Stamenkovic, V. R., Strmcnik, D., Lopes, P. P. \& Markovic, N. M. Energy and fuels from electrochemical interfaces. Nat. Mater. 16, 57-69 (2017).

3 Montoya, J. H. et al. Materials for solar fuels and chemicals. Nat. Mater. 16, 70-81 (2017).

4 Electrochemistry for a Sustainable World. Electrochem. Soc. Interface 29, 41-42 (2020).

5 Burke, M. S., Enman, L. J., Batchellor, A. S., Zou, S. \& Boettcher, S. W. Oxygen Evolution Reaction Electrocatalysis on Transition Metal Oxides and (Oxy)hydroxides: Activity Trends and Design Principles. Chem. Mater. 27, 7549-7558 (2015). $\mathrm{Hu}, \mathrm{C}$., Zhang, L. \& Gong, J. Recent progress made in the mechanism comprehension and design of electrocatalysts for alkaline water splitting. Energy Environ. Sci. 12, 2620-2645 (2019).

7 Suen, N.-T. et al. Electrocatalysis for the oxygen evolution reaction: recent development and future perspectives. Chem. Soc. Rev. 46, 337-365 (2017).

8 Song, F. et al. Transition Metal Oxides as Electrocatalysts for the Oxygen Evolution Reaction in Alkaline Solutions: An Application-Inspired Renaissance. J. Am. Chem. Soc. 140, 77487759 (2018).

9 Song, J. et al. A review on fundamentals for designing oxygen evolution electrocatalysts. Chem. Soc. Rev. 49, 2196-2214 (2020).

10 Hunter, B. M., Gray, H. B. \& Müller, A. M. Earth-Abundant Heterogeneous Water Oxidation Catalysts. Chem. Rev. 116, 14120-14136 (2016).

11 Peugeot, A. et al. Benchmarking of oxygen evolution catalysts on porous nickel supports. Joule 5, 1281-1300 (2021).

12 Kuznetsov, D. A. et al. Tuning Redox Transitions via Inductive Effect in Metal Oxides and Complexes, and Implications in Oxygen Electrocatalysis. Joule 2, 225-244 (2018).

13 Lemoine, K. et al. Investigation of mixed-metal (oxy)fluorides as a new class of water oxidation electrocatalysts. Chem. Sci. 10, 9209-9218 (2019).

14 Liang, K. et al. Overall Water Splitting with Room-Temperature Synthesized NiFe Oxyfluoride Nanoporous Films. ACS Catal. 7, 8406-8412 (2017).

15 Fan, X. et al. Defect-enriched iron fluoride-oxide nanoporous thin films bifunctional catalyst for water splitting. Nat. Commun, 9, 1809 (2018).

16 Chen, P. et al. Dynamic Migration of Surface Fluorine Anions on Cobalt-Based Materials to Achieve Enhanced Oxygen Evolution Catalysis. Angew. Chem. Int. Ed. 57, 15471-15475 (2018).

17 Xue, Y. et al. Electrochemical oxygen evolution reaction catalyzed by a novel nickel-cobaltfluoride catalyst. Chem. Commun. 54, 6204-6207 (2018).

18 Han, H., Woo, J., Hong, Y.-R., Chung, Y.-C. \& Mhin, S. Polarized Electronic Configuration in Transition Metal-Fluoride Oxide Hollow Nanoprism for Highly Efficient and Robust Water Splitting. ACS Appl. Energy Mater. 2, 3999-4007 (2019).

19 Wang, J. et al. Redirecting dynamic surface restructuring of a layered transition metal oxide catalyst for superior water oxidation. Nat. Catal. 4, 212-222 (2021).

20 Huang, Z.-F. et al. Strategies to Break the Scaling Relation toward Enhanced Oxygen Electrocatalysis. Matter 1, 1494-1518 (2019).

21 Brink, F. J., Withers, R. L. \& Norén, L. Nonstoichiometric, Rutile-Type, Solid Solutions in the FeIIF2-FeIIIOF System. J. Solid State Chem. 161, 31-37 (2001).

22 Fan, X. et al. High energy-density and reversibility of iron fluoride cathode enabled via an intercalation-extrusion reaction. Nat. Commun, 9, 2324 (2018).

23 Zhou, H. et al. Formation of Iron Oxyfluoride Phase on the Surface of Nano-Fe3O4 Conversion Compound for Electrochemical Energy Storage. J. Phys. Chem. Lett. 4, 37983805 (2013).

24 Zhu, J. \& Deng, D. Wet-Chemical Synthesis of Phase-Pure FeOF Nanorods as High-Capacity Cathodes for Sodium-Ion Batteries. Angew. Chem. Int. Ed. 54, 3079-3083 (2015). 
Lemoine, K. et al. New Amorphous Iron-Based Oxyfluorides as Cathode Materials for HighCapacity Lithium-Ion Batteries. J. Phys. Chem. C 123, 21386-21394 (2019).

26 Moysiadou, A., Lee, S., Hsu, C.-S., Chen, H. M. \& Hu, X. Mechanism of Oxygen Evolution Catalyzed by Cobalt Oxyhydroxide: Cobalt Superoxide Species as a Key Intermediate and Dioxygen Release as a Rate-Determining Step. J. Am. Chem. Soc. 142, 11901-11914 (2020). Bergmann, A. et al. Reversible amorphization and the catalytically active state of crystalline Co3O4 during oxygen evolution. Nat. Commun, 6, 8625 (2015). Burke, M. S., Kast, M. G., Trotochaud, L., Smith, A. M. \& Boettcher, S. W. Cobalt-Iron (Oxy)hydroxide Oxygen Evolution Electrocatalysts: The Role of Structure and Composition on Activity, Stability, and Mechanism. J. Am. Chem. Soc. 137, 3638-3648 (2015).

$29 \mathrm{Zu}, \mathrm{C} . \mathrm{X}$. \& Li, H. Thermodynamic analysis on energy densities of batteries. Energy Environ. Sci. 4, 2614-2624 (2011).

30 Hanaor, D. A. H., Xu, W., Ferry, M. \& Sorrell, C. C. Abnormal grain growth of rutile TiO2 induced by ZrSiO4. J. Cryst. Growth 359, 83-91 (2012).

31 Craig, M. J. et al. Universal scaling relations for the rational design of molecular water oxidation catalysts with near-zero overpotential. Nat. Commun, 10, 4993 (2019).

32 Bai, L., Lee, S. \& Hu, X. Spectroscopic and Electrokinetic Evidence for a Bifunctional Mechanism of the Oxygen Evolution Reaction**. Angew. Chem. Int. Ed. 60, 3095-3103 (2021).

33 Bediako, D. K., Surendranath, Y. \& Nocera, D. G. Mechanistic Studies of the Oxygen Evolution Reaction Mediated by a Nickel-Borate Thin Film Electrocatalyst. J. Am. Chem. Soc. 135, 3662-3674 (2013).

34 Grimaud, A. et al. Activating lattice oxygen redox reactions in metal oxides to catalyse oxygen evolution. Nat. Chem. 9, 457-465 (2017).

35 Zhang, N. et al. Lattice oxygen activation enabled by high-valence metal sites for enhanced water oxidation. Nat. Commun, 11, 4066 (2020).

36 Tao, H. B. et al. A General Method to Probe Oxygen Evolution Intermediates at Operating Conditions. Joule 3, 1498-1509 (2019).

37 Huang, Z.-F. et al. Chemical and structural origin of lattice oxygen oxidation in Co- $\mathrm{Zn}$ oxyhydroxide oxygen evolution electrocatalysts. Nat. Energy 4, 329-338 (2019).

38 Yang, C., Fontaine, O., Tarascon, J.-M. \& Grimaud, A. Chemical Recognition of Active Oxygen Species on the Surface of Oxygen Evolution Reaction Electrocatalysts. Angew. Chem. Int. Ed. 56, 8652-8656 (2017).

39 Yeo, B. S. \& Bell, A. T. Enhanced Activity of Gold-Supported Cobalt Oxide for the Electrochemical Evolution of Oxygen. J. Am. Chem. Soc. 133, 5587-5593 (2011).

40 Alrehaily, L. M., Joseph, J. M., Biesinger, M. C., Guzonas, D. A. \& Wren, J. C. Gammaradiolysis-assisted cobalt oxide nanoparticle formation. Phys. Chem. Chem. Phys. 15, 10141024 (2013).

41 Yang, J., Liu, H., Martens, W. N. \& Frost, R. L. Synthesis and Characterization of Cobalt Hydroxide, Cobalt Oxyhydroxide, and Cobalt Oxide Nanodiscs. J. Phys. Chem. C 114, 111119 (2010).

42 Bersani, D., Lottici, P. P. \& Montenero, A. Micro-Raman investigation of iron oxide films and powders produced by sol-gel syntheses. J. Raman Spectrosc. 30, 355-360 (1999).

43 de Faria, D. L. A., Venâncio Silva, S. \& de Oliveira, M. T. Raman microspectroscopy of some iron oxides and oxyhydroxides. J. Raman Spectrosc. 28, 873-878 (1997).

44 Grimaud, A., Hong, W. T., Shao-Horn, Y. \& Tarascon, J. M. Anionic redox processes for electrochemical devices. Nat. Mater. 15, 121-126 (2016).

45 Zhang, N. \& Chai, Y. Lattice oxygen redox chemistry in solid-state electrocatalysts for water oxidation. Energy Environ. Sci. (2021).

46 Greneche, J. M., Linares, J., Varret, F., Laligant, Y. \& Ferey, G. Mössbauer spectroscopy of the magnetic behaviour of the frustrated series AFeF5(H2O)2:A = Mn, Fe, Co, Ni. J. Magn. Magn. Mater. 73, 115-122 (1988).

47 VandeVondele, J. et al. Quickstep: Fast and accurate density functional calculations using a mixed Gaussian and plane waves approach. Comput. Phys. Commun. 167, 103-128 (2005). 
48 Hartwigsen, C., Goedecker, S. \& Hutter, J. Relativistic separable dual-space Gaussian pseudopotentials from H to Rn. Phys. Rev. B 58, 3641-3662 (1998).

49 VandeVondele, J. \& Hutter, J. Gaussian basis sets for accurate calculations on molecular systems in gas and condensed phases. J. Chem. Phys. 127, 114105 (2007).

50 Perdew, J. P., Burke, K. \& Ernzerhof, M. Generalized Gradient Approximation Made Simple. Phys. Rev. Lett. 77, 3865-3868 (1996).

51 Grimme, S., Antony, J., Ehrlich, S. \& Krieg, H. A consistent and accurate ab initio parametrization of density functional dispersion correction (DFT-D) for the 94 elements H-Pu. J. Chem. Phys. 132, 154104 (2010).

52 Hjorth Larsen, A. et al. The atomic simulation environment - a Python library for working with atoms. J. Phys.: Condens. Matter 29, 273002 (2017).

53 Al-Mahayni, H., Wang, X., Harvey, J.-P., Patience, G. S. \& Seifitokaldani, A. Experimental methods in chemical engineering: Density functional theory. The Canadian Journal of Chemical Engineering 99, 1885-1911 (2021).

54 Sanville, E., Kenny, S. D., Smith, R. \& Henkelman, G. Improved grid-based algorithm for Bader charge allocation. J. Comput. Chem. 28, 899-908 (2007).

55 Henkelman, G., Arnaldsson, A. \& Jónsson, H. A fast and robust algorithm for Bader decomposition of charge density. Comput. Mater. Sci. 36, 354-360 (2006).

$56 \mathrm{Yu}, \mathrm{M}$. \& Trinkle, D. R. Accurate and efficient algorithm for Bader charge integration. $J$. Chem. Phys. 134, 064111 (2011). 